\title{
The functions and roles of sestrins in regulating human diseases
}

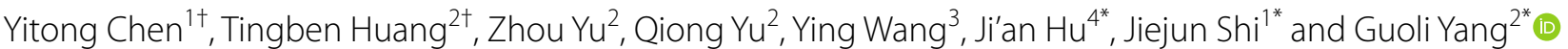

\section{*Correspondence:}

hja@zju.edu.cn; sjiejun@zju. edu.cn;7308037@zju.edu.cn

${ }^{\dagger}$ Yitong Chen and Tingben

Huang contributed equally

to this work

${ }^{1}$ Department

of Orthodontics,

Stomatology Hospital,

School of Stomatology,

Zhejiang University School

of Medicine, Clinical

Research Center for Oral

Diseases of Zhejiang

Province, Key Laboratory

of Oral Biomedical Research

of Zhejiang Province, Cancer

Center of Zhejiang University,

Hangzhou 310006, Zhejiang,

China

2 Department

of Implantology,

Stomatology Hospital,

School of Stomatology,

Zhejiang University School

of Medicine, Clinical

Research Center for Oral

Diseases of Zhejiang

Province, Key Laboratory

of Oral Biomedical Research

of Zhejiang Province,

Cancer Center of Zhejiang

University, Hangzhou 310006,

Zhejiang, China ${ }^{4}$ Department

of Oral Pathology,

Stomatology Hospital,

School of Stomatology,

Zhejiang University School

of Medicine, Clinical

Research Center for Oral

Diseases of Zhejiang

Province, Key Laboratory

of Oral Biomedical Research

of Zhejiang Province, Cancer

Center of Zhejiang University,

Hangzhou 310006, Zhejiang,

China

Full list of author information

is available at the end of the article

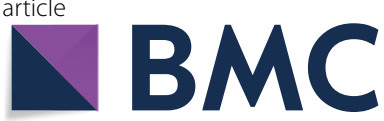

\begin{abstract}
Sestrins (Sesns), highly conserved stress-inducible metabolic proteins, are known to protect organisms against various noxious stimuli including DNA damage, oxidative stress, starvation, endoplasmic reticulum (ER) stress, and hypoxia. Sesns regulate metabolism mainly through activation of the key energy sensor AMP-dependent protein kinase (AMPK) and inhibition of mammalian target of rapamycin complex 1 (mTORC1). Sesns also play pivotal roles in autophagy activation and apoptosis inhibition in normal cells, while conversely promoting apoptosis in cancer cells. The functions of Sesns in diseases such as metabolic disorders, neurodegenerative diseases, cardiovascular diseases, and cancer have been broadly investigated in the past decades. However, there is a limited number of reviews that have summarized the functions of Sesns in the pathophysiological processes of human diseases, especially musculoskeletal system diseases. One aim of this review is to discuss the biological functions of Sesns in the pathophysiological process and phenotype of diseases. More significantly, we include some new evidence about the musculoskeletal system. Another purpose is to explore whether Sesns could be potential biomarkers or targets in the future diagnostic and therapeutic process.
\end{abstract}

Keywords: Sestrins, Biological functions, Human diseases, Musculoskeletal system disease, Biomarker, Therapeutic target

\section{Introduction}

Sesns comprise an evolutionarily conserved family of proteins universally found in animals. They are encoded by genes highly expressed in cells exposed to a variety of stresses, including oxidative stress, DNA damage, hypoxia, and starvation [1-3]. Vertebrates express three distinct Sesns (SESN1, SESN2, and SESN3) [1]. SESN1 is a member of the growth arrest and DNA damage-inducible gene (GADD) family [2, 4]. It is ubiquitously expressed in human tissues, mostly in skeletal muscle, heart, liver, and brain [5]. SESN2, known as hypoxia-inducible gene 95, is upregulated in cells under hypoxic conditions as well as oxidative stress, DNA damage, endoplasmic reticulum stressors, starvation, and high-fat diet [6-8]. It has also been identified as a key leucine sensor for the mTORC1 pathway in mammalian cells $[9,10]$. SESN2 is highly expressed in kidney, lungs, leukocytes, liver, gastrointestinal tract, and brain [5]. SESN1 and SESN2 are

(c) The Author(s), 2022. Open Access This article is licensed under a Creative Commons Attribution 4.0 International License, which permits use, sharing, adaptation, distribution and reproduction in any medium or format, as long as you give appropriate credit to the original author(s) and the source, provide a link to the Creative Commons licence, and indicate if changes were made. The images or other third party material in this article are included in the article's Creative Commons licence, unless indicated otherwise in a credit line to the material. If material is not included in the article's Creative Commons licence and your intended use is not permitted by statutory regulation or exceeds the permitted use, you will need to obtain permission directly from the copyright holder. To view a copy of this licence, visit http:// creativecommons.org/licenses/by/4.0/. 
regulated by the tumor-suppressor protein p53, while SESN3, the least reported one of the family, is majorly activated by FoxO transcription factors [11, 12]. SESN3 is highly expressed in brain, kidney, colon, small intestine, liver, and skeletal muscle [13, 14]. In normal physiology and organ homeostasis, Sesns control important cellular processes, including tissue growth, antioxidant response, metabolic homeostasis, nutrient sensing, autophagy, protein synthesis, and age-related pathologies. Different pathways are involved in the mechanisms of these processes, such as the AMPK/mTORC1 pathway, GATOR-Rags pathway, Keap1-Nrf2 pathway, and mTORC2-AKT pathway [14]. The structures, regulators, and functions of human Sesns are summarized in Table 1.

Identified as substantial anti-aging genes and regulators of reactive oxygen species (ROS) and mammalian targets of rapamycin complex 1 (mTORC1) [15], Sesns are associated with many age-related diseases, including cardiovascular diseases (CVDs), neurodegenerative diseases, chronic respiratory diseases, intervertebral disc degeneration

Table 1 Structure and functions of human sestrins

\begin{tabular}{|c|c|c|c|c|c|}
\hline Sestrins & Transcript variant & Crystal structure & Regulators & Functions & References \\
\hline hSesn1 & $3(\sim 48,55,68 \mathrm{kDa})$ & $\begin{array}{l}\text { Unknown (com- } \\
\text { posed mostly of } \\
\text { a-helical regions) }\end{array}$ & p53, FoXO & $\begin{array}{l}\text { (1) Inhibition of } \\
\text { ROS } \\
\text { (2) Nutrition sens- } \\
\text { ing (amino acid, } \\
\text { glucose, leucine) } \\
\text { (3) Inhibition of } \\
\text { mTORC1 } \\
\text { (4) Induction of } \\
\text { autophagy }\end{array}$ & {$[48,104,163,194]$} \\
\hline hSesn2 & $1(\sim 60 \mathrm{kDa})$ & $\begin{array}{l}\text { Two-fold pseudo- } \\
\text { symmetry with } 3 \\
\text { subdomains }\end{array}$ & $\begin{array}{l}\text { p53, Nrf2, ATF4, C/ } \\
\text { EBP } \beta, \text { JNKV c-Jun, } \\
\text { AP-1, HIF1 }\end{array}$ & $\begin{array}{l}\text { (1) Inhibition of } \\
\text { ROS, DNA damage, } \\
\text { and ER stress } \\
\text { (2) Nutrition sens- } \\
\text { ing (amino acid, } \\
\text { glucose, leucine) } \\
\text { (3) Inhibition of } \\
\text { cell growth and } \\
\text { mTORC1 } \\
\text { (4) Induction of } \\
\text { autophagy } \\
\text { (5) Maintaining } \\
\text { homeostasis of } \\
\text { glucose, insulin, } \\
\text { fatty acid, and } \\
\text { triglyceride }\end{array}$ & $\begin{array}{l}{[6,9,10,22,42,48} \\
57,86,136,162, \\
194]\end{array}$ \\
\hline hSesn3 & $2(44,53 \mathrm{kDa})$ & Unknown & $\begin{array}{l}\text { AP-1, FoxO1, } \\
\text { FoxO3 }\end{array}$ & $\begin{array}{l}\text { (1) Inhibition of } \\
\text { ROS } \\
\text { (2) Nutrition } \\
\text { sensing (amino } \\
\text { acid, glucose, and } \\
\text { leucine) } \\
\text { (3) Regulation } \\
\text { of mTORC1/ } \\
\text { mTORC2/PKB } \\
\text { (4) Induction of } \\
\text { autophagy } \\
\text { (5) Maintaining } \\
\text { homeostasis of } \\
\text { glucose, insulin }\end{array}$ & {$[22,39,194]$} \\
\hline
\end{tabular}

Sesn, Sestrin; Nrf2, nuclear factor erythroid 2-related factor 2; AP-1, activator protein 1; ATF4, activating transcription factor 4; C/EBP $\beta$, CCAAT/enhancer-binding protein beta; JNK, c-Jun N-terminal kinase; HIF1, hypoxia-inducible factor 1; FoxO, forkhead box protein $\mathrm{O}$; ROS, reactive oxygen species; mTORC1, mechanistic target of rapamycin complex 1; mTORC2, mechanistic target of rapamycin complex 2; PKB, protein kinase B, also known as Akt; AMPK, AMP-activated protein kinase 
(IDD), sarcopenia, etc. [2, 3, 16, 17]. As regulators of cellular homeostasis, Sesns are also connected with diseases such as diabetes, obesity, obstructive sleep apnea (OSA), neuropathic pain, epilepsy, and osteoarthritis. [16, 18-20].

In this review, we summarize the latest advances regarding the biological functions of human Sesns. In addition, the roles of Sesns in the pathophysiology of different human body systems and organs are discussed. Furthermore, we introduce the evidence of Sesns as potential biomarkers and therapeutic targets for various diseases. Nonetheless, most studies on Sesns are still in the experimental stages; thus, there is a long way to go before Sesns can be applied in clinical diagnosis and treatment. This article provides a comprehensive review on the roles of Sesns in the pathogenesis, diagnosis, and treatment of human diseases, and offers an outlook on future directions in Sesns research.

\section{Biological functions of Sesns in human pathophysiological processes}

Numerous studies have demonstrated that Sesns protect organisms against various pathologies, such as aging, metabolic homeostasis, lipid accumulation, and insulin resistance [21]. Sesns perform various biological functions by responding to different internal and external environmental stressors, including oxidative stress, genotoxic stress, hypernutrition, starvation, hypoxia, ER stress, etc. [2, 3, 21-23]. Here, we summarize the functions of Sesns under different unfavorable conditions (Table 2).

\section{Oxidative stress}

Oxidative stress is a phenomenon caused by the accumulation of excess reactive nitrogen species (RNS), ROS, and other reactive metabolic intermediates, which overwhelms the antioxidant system in living organisms $[1,3,14]$. Oxidative stress can cause damage to DNA, RNA, and other molecules such as proteins and lipids, contributing to aging, cell apoptosis, cardiovascular diseases, chronic kidney disease, neurodegenerative diseases, metabolic syndrome, etc. [3, 24-28]. Sesns are reported to be induced by oxidative stress in pathological conditions such as heart failure, colorectal diseases, atrial fibrillation, diabetes, cancer, chronic obstructive pulmonary disease, Alzheimer's disease (AD), and Parkinson's disease (PD) [14, 29-34]. Different mechanisms are reported to be involved in Sesns antioxidant reaction. Based on current evidence, SESN1 is induced by oxidative stress in a p53-dependent manner. SESN2 is activated not only in a p53-dependent manner, but through the NMDA receptor pathway, Nrf2 pathway, and JNK-AP-1 signaling axis as well $[1,35,36]$. The SESN2 gene is activated by mitochondrial specific ROS and dictates JNK specific inactivation of the apoptotic pathway [37]. SESN3 is stimulated by oxidative damage via activation of FoxO transcription factors [38, 39]. Although the mechanism of Sesns' antioxidant function is still unclear, several proteins or pathways may contribute to this process. They include the regeneration of peroxiredoxin AhpC, mTORC1\&Nox4 [13, 40, 41], the Keap1-Nrf2 pathway [3, 36], inhibition of uncoupling protein 1 expression by suppressing p38 MAPK [42], the dopamine D2 receptor [43], and the Akt/FoxO1 axis [44].

\section{Genotoxic stress}

Genotoxic stress is suggested to boost aging and activate DNA damage through mutations or genomic instability [45]. Also, it is a common challenge for cells exposed to toxic 
Table 2 Biological functions of sestrins in pathophysiological processes

\begin{tabular}{|c|c|c|c|c|c|}
\hline Conditions & $\begin{array}{l}\text { Upstream } \\
\text { pathways }\end{array}$ & Sestrins & $\begin{array}{l}\text { Downstream } \\
\text { pathways }\end{array}$ & Functions & References \\
\hline Oxidative stress & $\begin{array}{l}\text { p53, Nrf2/ARE, } \\
\text { FoxO1, FoxO3, } \\
\text { JNK/AP-1, PERK-C/ } \\
\text { EBP } \beta, \text { NMDA } \\
\text { receptor }\end{array}$ & Sesn $1 / 2 / 3$ & $\begin{array}{l}\text { AMPK/mTORC1, } \\
\text { Nrf2, } \\
\text { peroxiredoxin } \\
\text { AhpC, Nox4, } \\
\text { PDGFRß, p38 } \\
\text { MAPK, dopamine } \\
\text { D2 receptor, and } \\
\text { FoxO1 }\end{array}$ & $\begin{array}{l}\text { Increased expres- } \\
\text { sion of antioxidant } \\
\text { enzymes (trigger } \\
\text { antioxidant } \\
\text { response) }\end{array}$ & $\begin{array}{l}{[1,14,35,36,} \\
38-44]\end{array}$ \\
\hline Genotoxic stress & p53, FoxO3 & $\operatorname{Sesn} 1 / 2 / 3$ & $\begin{array}{l}\text { AMPK/mTOR, } \\
\text { AMPK/TOR, } \\
\text { p-Beclin1-Parkin, } \\
\text { JNK, PGC-1a }\end{array}$ & DNA repair & {$[8,48]$} \\
\hline Carcinogenesis & p53 & Sesn2 & mTORC2/Akt & Oncogenesis & [53] \\
\hline Hypernutrition & $\begin{array}{l}\text { Glucose, insulin, } \\
\text { fatty acid, and } \\
\text { triglyceride }\end{array}$ & $\operatorname{Sesn} 1 / 2 / 3$ & $\begin{array}{l}\text { AMPK, mTORC1- } \\
\text { S6K, mTORC2/Akt }\end{array}$ & $\begin{array}{l}\text { Maintain lipid and } \\
\text { glucose homeo- } \\
\text { stasis }\end{array}$ & {$[1,13,22,57,58]$} \\
\hline Nutrient starvation & $\begin{array}{l}\text { ATF4, Nrf2, JNK } \\
\text { c-Jun, FoxO1, } \\
\text { FoxO3, PGC-1a }\end{array}$ & Sesn $1 / 2$ & mTORC1 & $\begin{array}{l}\text { Inhibition of } \\
\text { necrosis and } \\
\text { apoptosis in cells, } \\
\text { represses majority } \\
\text { of protein transla- } \\
\text { tion, growth regu- } \\
\text { lation, autophagy } \\
\text { induction, regu- } \\
\text { late cellular energy } \\
\text { homeostasis }\end{array}$ & {$[35,37]$} \\
\hline Hypoxia & $\begin{array}{l}\text { p53, HIF-1, PI3K } \\
\text { Akt }\end{array}$ & Sesn2 & VEGF, AMPK-PHD & $\begin{array}{l}\text { Reduce hypoxic } \\
\text { damage }\end{array}$ & {$[6,8,54,68]$} \\
\hline ER stress & $\begin{array}{l}\text { PERK, PERK-C/ } \\
\text { EBP } \beta \text {, ATF4/Nrf2, } \\
\text { IRE1/XBP1, ATF6 }\end{array}$ & Sesn2 & $\begin{array}{l}\text { AMPK/mTORC1, c/ } \\
\text { EBP homologous } \\
\text { protein, p38, JNK, } \\
\text { UPR, PERK-ATF4- } \\
\text { CHOP }\end{array}$ & $\begin{array}{l}\text { Maintains } \\
\text { autophagy } \\
\text { homeostasis and } \\
\text { prevents apop- } \\
\text { tosis }\end{array}$ & [71-79] \\
\hline $\begin{array}{l}\text { Autophagy dys- } \\
\text { regulation }\end{array}$ & $\begin{array}{l}\text { AMPK/mTORC1, } \\
\text { p53 }\end{array}$ & Sesn2 & $\begin{array}{l}\text { AMPK/mTOR, PI3K } \\
\text { Akt/mTOR, AMPKa, } \\
\text { mTORC1-ULK1-S6, } \\
\text { autophagy protein } \\
\text { p62/SQSTM1, }\end{array}$ & $\begin{array}{l}\text { Autophagy induc- } \\
\text { tion }\end{array}$ & {$[1,15,82,83]$} \\
\hline $\begin{array}{l}\text { Mitochondrial } \\
\text { dysfunction }\end{array}$ & ATF4, RBX1, p53 & Sesn2 & $\begin{array}{l}\text { AMPK/mTOR, } \\
\text { AMPK/TOR, } \\
\text { p-Beclin1-Parkin, } \\
\text { JNK, PGC-1a }\end{array}$ & $\begin{array}{l}\text { Mitophagy induc- } \\
\text { tion }\end{array}$ & [85-87] \\
\hline $\begin{array}{l}\text { Immune dysregu- } \\
\text { lation }\end{array}$ & AMPK/mTORC1 & Sesn2 & $\begin{array}{l}\text { NLRP3 inflamma- } \\
\text { some; Erk-JNK-p38 } \\
\text { MAPK; AP-1, ULK1, } \\
\text { SQSTM1, AMPK } \\
\text { ERs }\end{array}$ & $\begin{array}{l}\text { Hyper-inflam- } \\
\text { mation; T-cell } \\
\text { senescence; anti- } \\
\text { inflammation }\end{array}$ & $\begin{array}{l}{[62,75,79,85} \\
89-91,94-97]\end{array}$ \\
\hline
\end{tabular}

Sesn, sestrin; Nrf2, nuclear factor erythroid 2-related factor 2; ARE, antioxidant responsive element; FoxO, forkhead box protein O; JNK, c-Jun N-terminal kinase; AP-1, activator protein 1; PERK, protein kinase RNA-like endoplasmic reticulum kinase; C/EBP $\beta$, CCAAT/enhancer-binding protein beta; NMDA, N-methyl-D-aspartate; AMPK, AMP-activated protein kinase; mTORC1, mechanistic target of rapamycin complex 1; Nox4, NADPH oxidase 4; PDGFR $\beta$, platelet-derived growth factor receptor beta; MAPK, mitogen-activated protein kinase; Beclin1, mammalian homolog of yeast ATG6; PGC-1a, peroxisome proliferator-activated receptor-gamma coactivator alpha; mTORC2, mechanistic target of rapamycin complex 2; S6K, ribosomal protein S6 kinase; HIF1, hypoxia-inducible factor 1; PI3K, phosphoinositide 3-kinase; PHD, prolyl hydroxylase; ATF4, activating transcription factor 4; IRE1, inositol-requiring enzyme 1; XBP1, X-box binding protein 1; ATF6, activating transcription factor 6; UPR, unfolded protein response; PERK, PKR-like ER kinase; CHOP, C/EBP homologous protein; ULK1, unc-51 like autophagy activating kinase 1; SQSTM1, sequestosome 1; RBX1, ring-box 1; NLRP3, Nod-like receptor family pyrin domain containing 3; Erk, extracellular signal-regulated kinase; ERs, estrogen receptors 
agents, including ultraviolet rays, chemotherapeutics agents, ionizing radiation, and overproduction of highly reactive molecules such as ROS, lipid peroxidation products, and DNA-alkylating agents $[3,46,47]$. SESN1 and SESN2 can both respond to genotoxic stress in a p53-dependent manner [8]. The ability of SESN1/2 to protect cells against DNA damage may be attributed to their redox activity and their redox-independent ability of inhibiting mTOR signaling [48]. Furthermore, Sesn2 can save energy from protein translation and membrane synthesis for DNA repair by activation of AMPK and inhibition of mTOR signaling [14].

\section{Carcinogenesis}

Carcinogenesis or tumorigenesis may be initiated and promoted by an imbalance between cell-intrinsic responses of target cells and changes in the tumor microenvironment caused by genotoxic stress [49]. Considering the ability of Sesns in inhibiting genotoxic damage and the oncogenic mTOR pathway, the role of Sesns in carcinogenesis is expected $[48,50]$. Previous studies on colon cancer, lung carcinoma, and lung adenocarcinoma have proved the tumor-suppressive functions of Sesns [2, 51, 52]. Surprisingly, Sesns are also vital in maintaining the viability of cancers under specific conditions. These cancers include squamous cell carcinoma (SCC), melanoma and hepatocellular carcinoma [37, 53]. The oncogenic function of Sesns may be ascribed to their protection against energetic stress via Akt and mTOR signaling [54]. Further studies are needed to elucidate the dual role of Sesns in different neoplastic diseases for potential anti-tumor therapeutic approaches.

\section{Hypernutrition}

Hypernutrition promotes the development of obesity and metabolic syndromes such as type 2 diabetes, insulin resistance, and elevated blood glucose levels [1, 55]. Sesns have been reported to be induced in organs such as the muscle, adipose tissue, and liver in animal models of type 2 diabetes and obesity $[22,56]$. A previous study reported that SESN2-deficient obesity mouse developed glucose intolerance, insulin resistance, and hepatosteatosis, all of which were augmented by mTORC1-S6K activation in response to nutritional abundance $[1,57]$. Tao et al. demonstrated that SESN3 protected high-fat-fed mice against insulin resistance through the mTORC2/Akt pathway [13]. Therefore, evidence suggests that Sesns are essential in maintaining metabolic homeostasis and protecting against hypernutrition $[13,22,58-61]$.

\section{Nutrient starvation}

SESN2 is the major Sesns family member that is activated under nutrient starvation [54]. Upon energy deprivation, SESN2 protects against cell apoptosis, and regulates protein synthesis and autophagy via the AMPK/mTORC1 pathway [62-64]. This proves that SESN2 is a crucial nutrient sensor that modulates energy homeostasis. Due to these functions, activation of Sesns may enhance the survival of tumor cells under the condition of limited nutrition. Different mechanisms are involve in Sesns induction by deficiency of different nutrients. Under glucose scarcity, SESN2 elevation may depend on PGC-1 $\alpha$ activation [37]. Under serum deprivation, the c-Jun N-terminal kinase (JNK) 
pathway activation and its downstream factor c-Jun phosphorylation may activate the expression of Sesns [35].

\section{Hypoxia}

Hypoxia is one of the most severe metabolic insults, which is associated with a variety of pathological conditions, such as pulmonary arterial hypertension, arrhythmia, hypoxicischemic encephalopathy (HIE), myocardial ischemia injury and cancer [65, 66]. SESN1 and SESN2 can be induced by hypoxia in many human cancer cell lines [1]. The pathways vary among the isoforms. SESN1 is activated strictly in a p53-dependent manner [54], while SESN2 could be activated by hypoxia through the HIF-1-dependent pathway [67] and HIF-1-independent pathway [8]. The PI3K/Akt pathway may also be involved in the Sesn 2 transcriptional process [54]. Sesns are found to protect against several hypoxia related pathological conditions. Harmful chemicals such as 2-deoxyglucose and metformin (an inhibitor of mitochondrial respiration) stimulate the expression of SESN2 [54]. In hypoxic-ischemic mouse models, SESN2 was found to inhibit VEGF production and attenuate the blood-brain barrier permeability to reduce brain damage [68]. A previous study with colorectal cancer cells and mouse xenograft models suggested that SESN2 inhibited tumorigenesis by promoting the degradation of HIF-1 $\alpha$ via AMPKPHD regulation [6].

\section{ER stress}

ER stress occurs when misfolded proteins accumulate due to pathological conditions in normal aging and a variety of degenerative diseases, such as cancer, obesity, PD, AD, IDD, and sarcopenia [69,70]. ER stress causes tissue damage by impairing a series of molecular and biochemical processes, including protein folding and protein transportation [7].

Studies have shown that ER stress induces SESN2 expression through the PERK and IRE1/XBP1 transduction pathways [3]. Ding et al. demonstrated that glucose starvation activated SESN2 via ATF4 and Nrf2 activation [71]. In the absence of SESN2, cells are highly susceptible to ER-related pathologies, including mitochondrial dysfunction, lipid accumulation, protein aggregate formation, and apoptosis [72-74]. SESN2 acts as a crucial regulator in ER stress-related atherosclerosis [75], liver injury [76, 77], spinal cord injury [78], and sepsis-related dendritic cell apoptosis [79]. The AMPK/mTORC1 pathway, CCAAT-enhancer-binding protein homologous protein, phosphorylation of both p38 and JNK, and sestrin-mediated unfolded protein response contribute to the protective mechanisms of SESN2 against ER stress-associated diseases [72, 75-77].

\section{Autophagy dysregulation}

Autophagy refers to cellular mechanisms by which cells break down and recycle damaged or toxic cellular structures to maintain organelle function and cell homeostasis [80]. Autophagy impairment comes from accumulation of protein aggregates, damaged mitochondria, and ROS. This deficiency can result in diverse neurodegenerative diseases, such as Parkinson's, Alzheimer's, and Huntington's diseases [81]. Sesns promote autophagy by activating AMPK and inhibiting mTORC1, thus attenuating 
neurodegenerative diseases $[15,22,82]$. In addition, the induction of autophagy by p53-SESN2 enhances anticancer processes in various human carcinoma cells [83].

Mitophagy is a specific form of autophagy that is vital in ensuring the functionality and integrity of the mitochondrial network. Dysregulation of mitophagy results in mitochondrial ROS accumulation and is crucial in diverse degenerative pathologies such as PD, AD, Leber's hereditary optic neuropathy, inflammation, sepsis aging, and cancer [5, 84]. As a positive regulator of Parkin-mediated autophagy, SESN2 is essential in mitochondrial homeostasis [5]. SESN2 can regulate mitophagy by enhancing the targeting of impaired mitochondria for lysosomal degradation and via regulation of Parkin E3 ligase migration to damaged mitochondrial surface [85, 86]. It is demonstrated that the p53-SESN2 axis provides a protective mechanism against acute kidney injury by regulating autophagy and mitophagy in renal tubules [87]. Kumar et al. found that SESN2 could promote cell death under long-term mitochondrial damage rather than regulating the mitophagy upon normal mitochondrial stress [88].

\section{Immune dysregulation}

Immune dysregulation is associated with a variety of diseases, including infections and malignancy [89]. Recently, the involvement of SESN2 in immune cells, including macrophages, monocytes, T cells, NK cells, and B cells, has been studied [54, 90]. SESN2 protected macrophages from apoptosis and alleviated the excessive inflammatory response of macrophages in diseases such as myocardial infarction [91-93]. Monocytes can also be regulated by Sesn 2 to reduce the damage caused by LPSinduced inflammation, atherosclerosis, high-glucose status, high-fat condition, and sepsis [76, 84, 94]. Mechanically, SESN2 knockdown significantly increases the secretion of pro-inflammatory cytokines, regulates monocyte polarization, and increases monocyte recruitment to the vascular endothelial cells by downregulating AMPK signaling and the ER stress pathway. Additionally, SESN2 maintains immunological homeostasis by activating mitophagy in monocytes to restrain the NLRP3 inflammasome hyperactivation [85].

However, the effects of Sesns in T cells may oppose their functions in other cells [54]. Sesns expression and Sesn-MAPK activation immune-inhibition complex levels were higher in $\mathrm{T}$ cells from older humans and mice [95]. Inhibition of SESN1/2/3 in senescent $\mathrm{T}$ cells enhanced cell proliferation, telomerase activity, and IL-2 synthesis viability, demonstrating an anti-aging effect $[21,95]$. A recent study in the acute colitis mouse model suggested that SESN3 might be vital in generating pathogenic Th1 and Th17 cells mediated by macrophage in inflammatory bowel diseases [96].

Also, Sesns could induce the reprogramming of non-proliferative senescent-like $\mathrm{CD} 8(+) \mathrm{T}$ cells to acquire a natural killer function, which may be vital to surveilling and eliminating senescent cells during aging [89]. In ovarian cancer cells, SESN2 and SESN3 restrained NK cell-mediated cytotoxic activity through the AMPK and mTORC1 signaling [97]. Experimental results in mouse B cells indicate that SESN2 may be a therapeutic target in IgE-mediated allergic diseases since SESN2-AMPK signaling selectively promotes IgE class switching and IgE production [90]. In dendritic cells, SESN2 also exerts a protective effect against sepsis by inhibiting apoptotic ER stress signaling [79]. 


\section{The roles of Sesns in human diseases}

Sesns protect against various environmental stressors and regulate the AMPK/mTORC1 pathway. Moreover, Sesns regulate cell metabolism and cellular homeostasis in both normal and diseased states [70]. The protective effects of Sesns in all sorts of human diseases have significantly attracted researchers (Fig. 1).

\section{Cardiovascular diseases}

CVDs are the main cause of death worldwide [98]. Studies have shown that Sesns play important protective roles in various CVDs, including atherosclerosis (AS), acute myocardial infarction (AMI), heart failure, hypertension, myocardial hypertrophy, atrial fibrillation, and myocardial fibrosis $[3,99,100]$. The role of Sesns in CVDs is associated with their versatile functions in cardiology. Their functions include reducing ROS level, alleviating inflammation, and attenuating aging. Sesns could also enhance autophagy, inhibit fibroblast proliferation, modulate substrate metabolism, and maintain the redox homeostasis $[3,98,99]$.

CVDs such as heart failure, atrial fibrillation, hypertension, and AS are strongly associated with excessive ROS [3]. Sesns can reduce production of ROS via mTORC1-independent mechanisms and protect cells against ROS accumulation by promoting the cyclic absorption of over-oxidized peroxidase [42, 43]. This signifies the exciting potential for therapeutic and diagnostic applications in CVDs [92]. In patients with coronary heart disease (CAD), aortic dissection, and chronic heart failure (CHF), the level of SESN2 is elevated and appears to be related to the severity of the disease [101-103].

The macrophage-mediated inflammatory response also has important roles in CVDs such as AS, AMI and heart failure [3,33]. M1 macrophages promote secretion of matrix metalloproteinases and pro-inflammatory factors to promote the development of CVDs, while M2 macrophages tend to secrete anti-inflammatory factors $[8,13]$. Sesns affect the level of inflammatory factors and regulate the M1/M2 macrophage balance via the

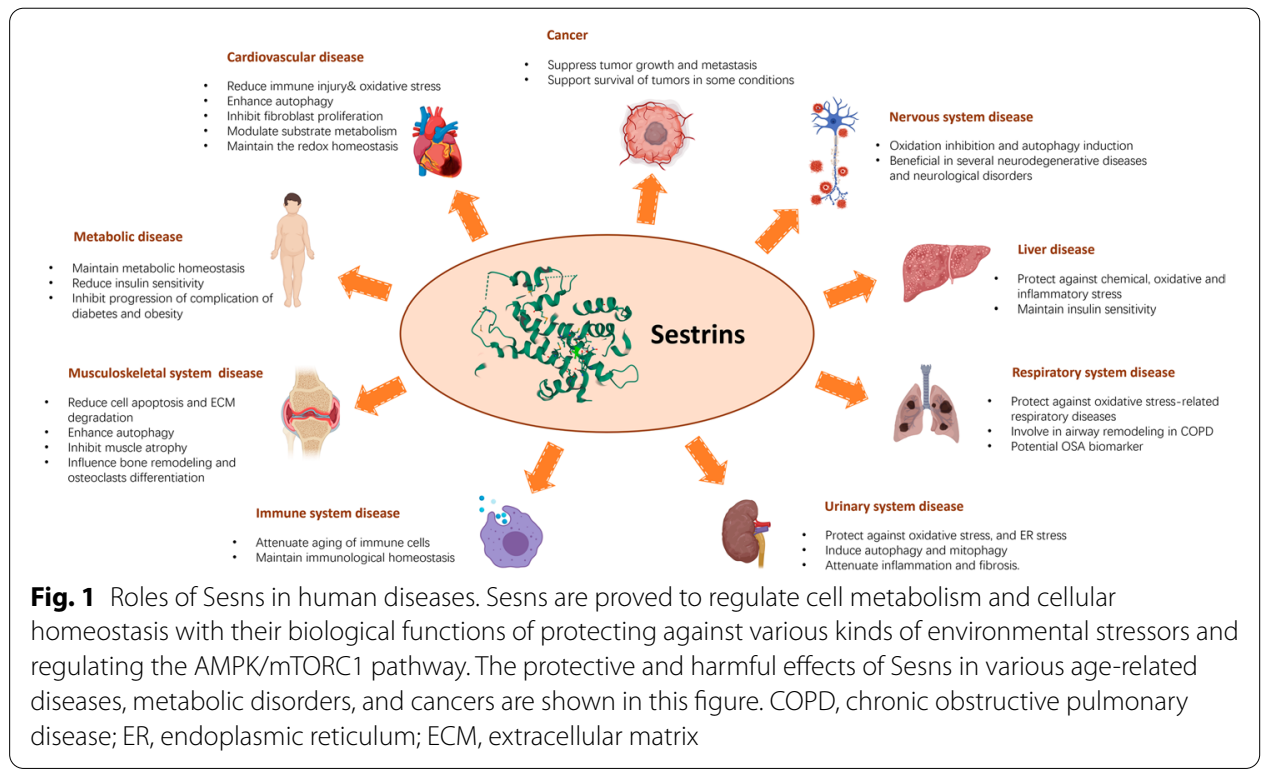


AMPK-mTOR pathway and eventually result in an anti-inflammatory response $[3,12$, 24, 104].

Myocardial ischemia and reperfusion (I/R) injury may lead to cardiac arrhythmia and heart failure [105]. Sesns may protect the cardiovascular system against I/R injury by attenuating ROS accumulation and enhancing autophagy [106]. Additionally, Sesns could prevent age-related intolerance to ischemic heart disease by LKB1-mediated AMPK activation and substrate metabolism modulation [107, 108].

\section{Metabolic diseases}

Metabolic disorders, such as obesity-associated CVDs, diabetes, and non-alcoholic fatty liver disease, are marked by the regulation of AMPK and mTOR [2]. Sesns have been demonstrated to play a critical role in metabolic control and glucose homeostasis by regulating AMPK/mTORC1 [109]. In contrast, the effects of SESN3 on insulin sensitivity and glucose metabolism is probably associated with mTORC2-Akt signaling with little involvement of AMPK [14]. Different Sesns isoforms have different responses to metabolic disorders. SESN2 accumulated in the muscle, liver, and adipose tissues in a mouse model of type 2 diabetes and obesity [22], whereas SESN1 decreased in the skeletal muscle and SESN3 decreased in the liver and adipose tissue in patients with high-fat diet and diabetics [29]. Lack of SESN2 increased the progression of diabetes, obesity-induced insulin resistance, and the severity of hepatosteatosis caused by obesity [22]. Moreover, a recent report showed that exercise could induce SESN2 and increase insulin sensitivity through autophagy [110].

\section{Nervous system diseases}

Various neurodegenerative diseases and neurological disorders are related to excessive oxidative stress with compromised antioxidant capacity and accumulation of misfolded proteins $[111,112]$. Due to their biological functions in anti-oxidation and autophagy promotion, protective roles of Sesns are gradually appreciated in neurodegenerative diseases and neurological disorders [19, 113-116]. The former diseases include AD, PD, Huntington's disease (HD), and amyotrophic lateral sclerosis (ALS). The latter refer to seizures, neuropathic pain, ischemic stroke, and neonatal hypoxic-ischemic encephalopathy. The evidence of SESN1 and SESN3 in regulating the nervous system is relatively scarce since most studies focused on SESN2. This calls for further investigation into the potentially unique functions of these two proteins [113].

\section{Liver diseases}

The liver is a metabolically active organ that is susceptible to oxidative damage. Since Sesns are regarded as key inhibitors of oxidative stress, the roles of Sesns in liver diseases have been widely investigated. Sesns are associated with various liver diseases, including hepatocyte injury, hepatitis, nonalcoholic fatty liver disease (NAFLD), and liver cancers such as hepatocellular carcinoma (HCC) [117]. The hepatoprotective effect of SESN2 may be due to its regulation upon the Nrf2/Keap1 pathway to reduce the liver's susceptibility to oxidative damage [118]. Inhibition of mitochondrial dysfunction and remittance of ER stress-associated liver damage may also explain this effect [118]. The action of Sesns against hepatic metabolic stress, liver infectious disease and HCC is discussed 
in other sections. Accumulated reports indicate that Sesns may be promising targets in liver disease; however, the exact mechanisms of action of Sesns against liver diseases are still unclear [118].

\section{Respiratory system diseases}

Recent studies have shown that Sesns are involved in many oxidative stress-related respiratory diseases, including chronic obstructive pulmonary disease (COPD), asthma, acute respiratory distress syndrome (ARDS), OSA, and CS-induced emphysema [119-121].

SESN2 is upregulated in the lungs of COPD patients and mutational inactivation of SESN2 partially rescues the development of emphysema in mouse models by activation of PDGFR $\beta$ signaling or TGF $\beta$ signaling [122-124]. These results suggest that COPD patients might benefit from antagonists of Sesns function [122].

Airway remodeling is an important factor associated with the severity of lung function reduction in COPD. Zhang et al. found that the serum SESN2 level is positively related to airway remodeling [18]. This suggests that SESN2 may be a novel biomarker for prognosis evaluation of COPD patients.

A recent clinical study demonstrated a relationship between SESN2 and asthma [109]. Both during and after asthma exacerbation, the SESN2 level increased [121, 125]. The imbalance between oxidative stress and antioxidant activity in severe asthma patients may explain the change of Sesn level [125].

OSA is characterized by repeated apnea during sleep and intermittent hypoxia, which can lead to serious complications, including coronary heart disease, type 2 diabetes, hypertension, cerebrovascular accident, and stroke [119, 120]. Intermittent hypoxia and the following oxidative stress may cause these complications, which led to research on stress-inducible proteins such as Sesns. Plasma and urinary SESN2 levels were found to increase in OSA patients and to be associated with the severity of OSA, implying that SESN2 can be an important marker of the severity of OSA and the effect of treatment $[119,120,126]$.

\section{Urinary system diseases}

Sesns are assumed to play a critical protective role in the kidneys with its functions of mediating stressors such as oxidative stress, ERs, mitochondrial dysfunction, and autophagy, as well as attenuating inflammation and fibrosis [127]. Indeed, studies have shown that SESN2 is involved in acute kidney injury (AKI), glomerular parietal epithelial cells (PECs) injury, glomerular mesangial cell (MC) damage, and diabetic kidney disease (DKD) [127].

SESN2 is upregulated in proximal tubular cells during I/R-induced AKI in vivo, while overexpression of SESN2 induced autophagy in renal tubular cells [87]. Decreased expression of SESN2 in the renal proximal tubules causes ROS overproduction, high renal vascular blood pressure, and renal hypofunction [43]. In addition to AKI, SESN2 has been reported to confer protection in PECs, MCs, and DKD [43]. The mechanism may relate to Sesns' anti-apoptosis effects, regulation of mTOR, activation of AMPK/ Nox4, etc. $[128,129]$. 
DKD, a common diabetic complication that causes end-stage renal disease, is the major cause of chronic kidney disease worldwide [127]. In a human proximal tubule cell line (HK-2) model, over-expression of SESN2 repressed DKD-induced epithelial-mesenchymal transition and ER stress, demonstrating the therapeutic function of SESN2 in DKD [130]. Additionally, SESN2 is reported to improve mitochondrial dysfunction in podocytes under high glucose conditions [131].

Gout is a common type of arthritis caused by elevated serum uric acid (SUA) levels. SESN2 is identified to be one of the genes that potentially influence SUA, providing insights into the functions of Sesns in the pathogenesis, treatment, and prevention of hyperuricemia/gout [132].

\section{Immune system related diseases}

Sesns are expressed in multiple immune cells such as macrophages, monocytes, NK cells, and T lymphocytes [85, 95, 97, 133]. Sesns suppress the inflammatory response, inhibit $\mathrm{T}$ cell immunity, and support macrophage survival $[85,92,134]$. The expression of Sesns might impact the function of immune cells by activating AMPK, suppressing mTORC1 signaling, inhibiting the JNK pathway, or inhibiting the NLRP3 inflammasome from consistent activation [62].

Macrophages are the first line of immune cells that can recognize and eliminate endotoxin [135]. A previous study showed that NO and hypoxia up-regulate SESN2 in macrophages [91]. Lipopolysaccharide (LPS), a representative Toll-like receptor 4 ligand, significantly increases SESN2 expression in macrophages [136]. The Toll-like receptormediated induction of SESN2 is dependent on the Nrf2-ARE pathway, AP-1, and the suppression of ubiquitin-mediated degradation of SESN2 and may protect cells against endotoxin toxicity [136].

NK-92 cells are widely used for immunotherapy in cancer due to their high tumoral potency [97]. SESN2 and SESN3 expression levels of NK-92 cells were found to be much higher in ovarian cancer mouse samples, indicating that the tumor microenvironment increased the expression of Sesns [97]. Moreover, overexpression of SESN2 and SESN3 impaired the tumoricidal effect of NK-92 cells, suggesting that downregulating Sesns expression may benefit NK-92 cell-based cancer therapy.

\section{Musculoskeletal system diseases}

The musculoskeletal system includes the skeletal system, which comprises bones and cartilages, and the muscular system, which comprises all the body muscles. Recent studies have demonstrated the function of Sesns in musculoskeletal system diseases, such as IDD, osteoarthritis (OA), and sarcopenia. (Fig. 2).

IDD is the primary cause of low back pain and the main factor of functional disability, which significantly affects the quality of life among the elderly population and in some young people [137]. The degeneration of intervertebral disc tissue starts before the degeneration of other musculoskeletal tissues and is often asymptomatic [137]. Although the pathophysiology of IDD is not yet well understood, it is associated with cell senescence, excessive apoptosis, impaired autophagy, pro-inflammatory cytokine storm, and degradation of the extracellular matrix (ECM) [138-141]. As suppressors of cell aging and promotors of autophagy, Sesns are thought to be involved in the IDD 


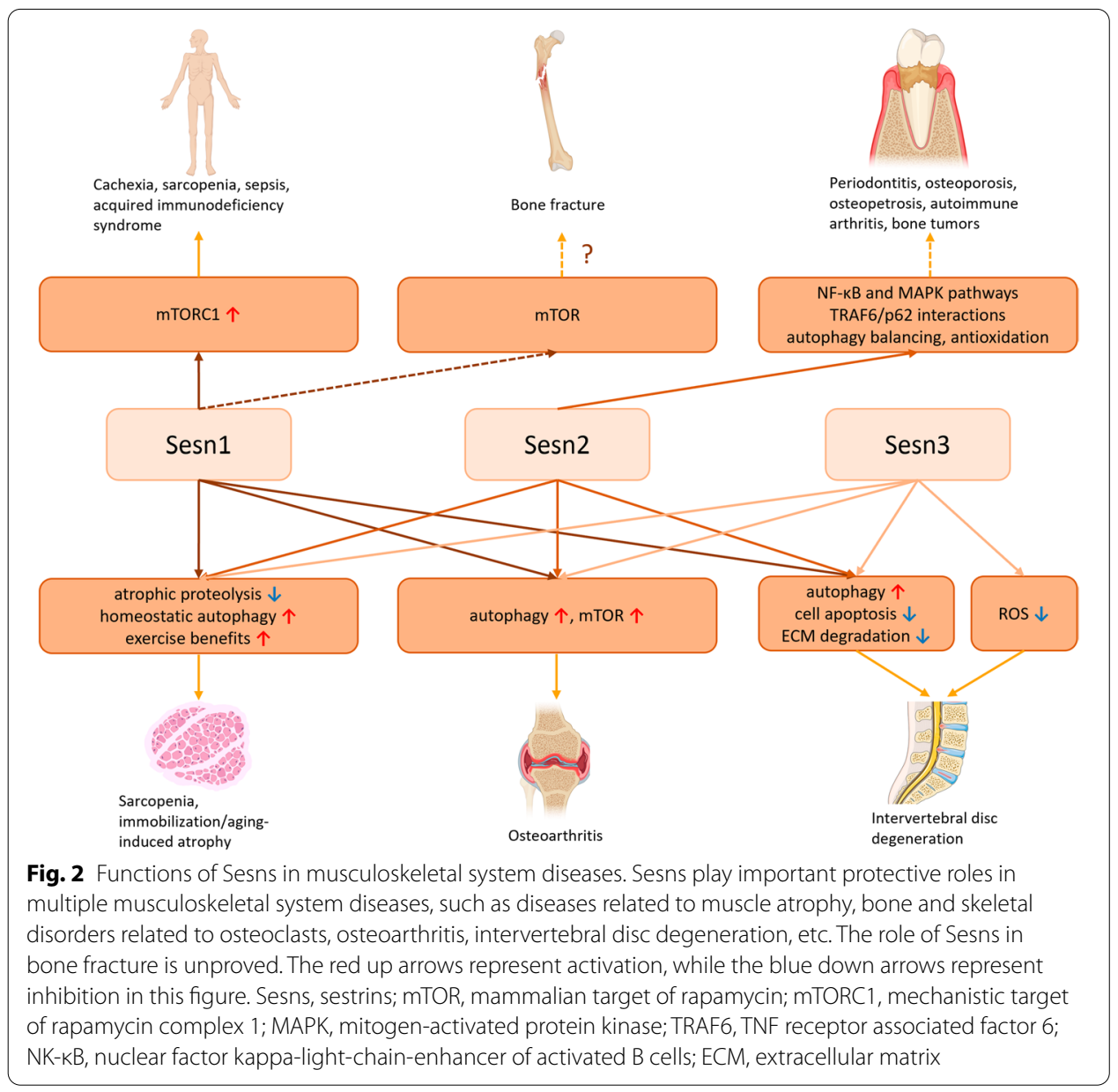

process [70, 141, 142]. Tu et al. demonstrated that the expression of SESN1, 2, and 3 markedly decreased in degraded human nucleus pulposus cells but increased after stimulation by an ER stress inducer [70]. Also, knockdown of SESN2 in stress-induced nucleus pulposus cells notably increased cell apoptosis and ECM degradation, while SESN2 overexpression repressed IDD by enhancing autophagy [70]. Consequently, inhibition of Sesns may be related to an essential cellular dysfunction mechanism in IDD. A recent study showed that FoxO, a family of transcription factors that regulate tissue homeostasis and longevity, was reduced in the degraded lumbar intervertebral disc [16]. As a key FoxO downstream target, SESN3 is also decreased in aged lumbar discs, which may compromise the ability of intervertebral disc cells to neutralize ROS [16].

OA is the most prevalent joint disease that affects all synovial joints (hand, hip, knee, and spine) [143]. Risk factors for OA include genetic tendency, aging, metabolic disorders, obesity, previous injury, negative lifestyle, and female gender [144]. $\mathrm{OA}$ is mainly characterized by progressive degradation of the articular cartilage and accompanying secondary episodic synovitis and bone remodeling [143]. Several studies show that Sesns play a protective role in cellular homeostasis in OA cartilage [20, 145]. PCR and immunohistochemistry results show that SESN1, SESN2 and SESn3 
expression is suppressed in OA-affected cartilage [20]. In siRNA-mediated all Sesns knockdown and SESN2 overexpression experiments, Sesn supports chondrocyte survival under stress conditions by activating autophagy through mTOR signaling [20].

Sarcopenia is an age-related disease of skeletal muscle mass loss. The pathologies are connected with many factors, including inactivity, malnutrition, degeneration of neuromuscular junction, and skeletal muscle cell senescence [146, 147]. Muscle mass is related to survival under several pathological conditions, including sepsis, acquired immunodeficiency syndrome, sarcopenia, and cachexia [148]. Reduced activity, decreased appetite, and nutrient consumption may contribute to the muscle loss. Studies from Drosophila and mouse models found that knockout of Sesns resulted in muscle degeneration, providing a connection between Sesns and muscle growth [40]. Segalés and colleagues identified SESN1 and SESN2 as protectors of the muscle against aging-induced atrophy, probably through the inhibition of atrophic proteolysis and activation of homeostatic autophagy [147]. Interestingly, recent studies have shown that Sesns could maintain the homeostasis of muscle stem cells against aging and metabolic insults by inhibiting mTORC1 and maintaining the quiescent state [149].

Regular exercise is an effective intervention to slow down the progression of sarcopenia and increase muscle mass $[150,151]$. Sesns have recently been reported to be strongly associated with exercise benefits [110, 152-154]. Kim et al. showed that Sesns are molecular transducers of the beneficial effects of exercise, including enhanced endurance and improved insulin signaling [153]. Sesns expression decreases during inactivity [147]. Loss of Sesns inhibits exercise benefits, while overexpression of them reverses the immobilization/aging-related atrophy $[151,153]$. Sestrin proteins are differentially regulated in different training models [155]. Aerobic exercise increases SESN2 protein expression [156], while acute resistance exercises transiently regulate SESN2 [155]. Liu et al. found that long-term endurance exercise raised the protein expression of SESN2 and SESN3, and the basic level of muscle autophagy [110]. Nevertheless, in a recent study, the protein or mRNA expression level of SESN2 and SESN3 or the basal phosphorylation state of SESN2 was not modified after a 12-week long-term resistance training program, whereas the protein expression of SESN1 was induced in human skeletal muscle [155].

Apart from endurance exercise, dietary supplementation of essential amino acids can also lessen the loss of muscle mass [157]. Among all the essential amino acids, leucine is of critical importance since it stimulates skeletal muscle protein synthesis to the same degree as that of a complete mixture of amino acids [158]. Activation of mTORC1 is essential for muscle protein synthesis (MPS) after protein feeding [159-161]. Sesns play an important role in mTORC1 regulation and SESN2 has been considered as a leucine sensor $[10,162]$. The expression of Sesn isoforms differs among various tissues. In the skeletal muscle, SESN1 was more abundant than SESN2 and SESN3. Studies have implicated that oral administration of leucine to fasted rats promotes the dissociation of SESN1 from GATOR2 rather than SESN2 or SESN3, indicating that SESN1 regulates leucine-induced activation of mTORC1 in skeletal muscle [162, 163].

Fractures, mostly caused by injury, are significant public health burdens. The physiological process of fracture healing involves a series of well-organized events, including the recruitment of regulatory factors and cell types [164]. Recent studies have suggested 
that mTOR signaling may be involved in regulating cartilage development and pre-osteoblast differentiation [165]. As negative regulators of mTOR signaling, Sesns are thought to be involved in fracture healing. However, a recent study showed that serum SESN1 levels in bone fracture patients did not differ from those in healthy people, while mTOR levels increased significantly [166]. A limitation of this study is that mTOR and SESN1 levels were only measured on the first day after a fracture. Further clinical studies are needed to explore the potential role of mTOR signaling in the fracture healing process.

A large variety of bone diseases, such as periodontitis, osteoporosis, osteopetrosis, autoimmune arthritis, and bone tumors, are related to the homeostatic equilibrium of bone formation and bone resorption [167-170]. A recent study in mice showed that SESN2 influences bone remodeling and osteoclast differentiation by NFATc1 activation and TRAF6/p62 interaction [171]. Abnormal formation of osteoclasts is vital in various bone and skeletal disorders, so the exact role of Sesns in the maintenance of bone homeostasis and treatment of bone remodeling related bone diseases deserves further investigation.

\section{Cancer}

Cancer is strongly associated with oxidative stress, gene mutation, and metabolic dysregulation. Unlike other cells, cancer cells favor conditions of oxidative stress. It has been reported that mTOR hyperactivation could lead to tumorigenesis and tumor progression [2]. Therefore, as ROS and mTOR inhibitors, Sesns may confer tumor suppressor activity, and be employed in the diagnosis and treatment of multiple cancers [2,3]. Accumulating evidence demonstrates that most forms of cancers are accompanied by remarkable change of Sesn expression. Sesns can suppress cell growth and proliferation in cancers such as colorectal cancer, lung carcinoma, and endometrial cancer [33, 52, 172-174].

To survive in a hypoxic tumor microenvironment, most cancer cells induce expression of HIF-1 $\alpha[2,175]$. A study by Seo et al. demonstrated that overexpression of SESN2 suppressed the accumulation of HIF-1 $\alpha$, hence preventing the metastasis of colorectal cancer [6]. Clinical evidence from patients with colon cancer showed that the expression of SESN2 was downregulated and SESN2 levels were negatively correlated with chemotherapy resistance, which further supports the view that SESN2 can serve as a tumorsuppressive protein and a feasible prognostic marker in various cancers such as NSCLC and colon cancer [2]. However, a recent study by Shin et al. showed that SESN2 levels increased in endometrial cancer cells [174]. The study also proved that knockdown of SESN2 could promote cancer cell growth, migration and ROS accumulation via the mTORC1 pathway, indicating the anti-cancer potential of SESN2 and mTORC1 pathway inhibitors in endometrial cancer. Ding et al. reported that SESN2 can inhibit the development of lung adenocarcinoma by regulating X-linked inhibitor of apoptosis protein and inducing cell death through the activation of death receptors [52].

Sesns are also vital in maintaining the viability of cancers under specific conditions [53, 83, 176, 177]. For instance, SESN2 supported the survival of melanoma cells and SCC cells after ultraviolet B radiation and chemotherapeutics [53], and hepatocellular carcinoma cells under glucose limitation [37]. These findings indicate that Sesns may promote tumorigenesis and chemoresistance of cancer cells [53, 97]. In addition, the 
activation of SESN2 in tumor cells can induce an autophagic response, thus facilitating the growth of tumor cells under limited oxygen and nutrient conditions [83]. Further investigations are needed to illustrate the advantageous or disadvantageous roles of Sesns in cancers and to determine their potential applications in radiotherapy or chemotherapy [3].

\section{Future directions: Sesns as biomarkers and therapeutic targets of diseases}

Given these multiple effects, members of the Sesns protein family are potential biomarkers and treatment targets in aging-related diseases, metabolic diseases, bone diseases, and various other diseases [2]. Here, we list the potential functions of Sesns and their regulators in modern medicine (Fig. 3).

\section{Sesns for disease diagnosis}

Sesns levels can reflect the status of many diseases, which could be used as valuable biomarkers for diagnosis. For instance, the SESN2 level was suggested to be an early biomarker of atherogenesis, CAD, OSA and sarcopenia [17, 94, 103]. The sensitivity and specificity of SESN2 for OSA diagnosis were respectively $61.90 \%$ and $90.70 \%$, which are clinically valuable levels [126]. What is more, SESN3 as a colon-specific marker might improve the detection of acute graft-versus-host disease (aGvHD) [178].

Sesns levels could also be prognostic markers for predicting the treatment outcome. Plasma or urinary SESN2 levels were reported to reflect the severity of CAD, CHF, coronary stenosis, OSA and COPD [102, 103, 119]. SESN2 levels might be positive prognostic markers in HCC [179], NSCLC [172], and neurodegenerative diseases such as AD [2].

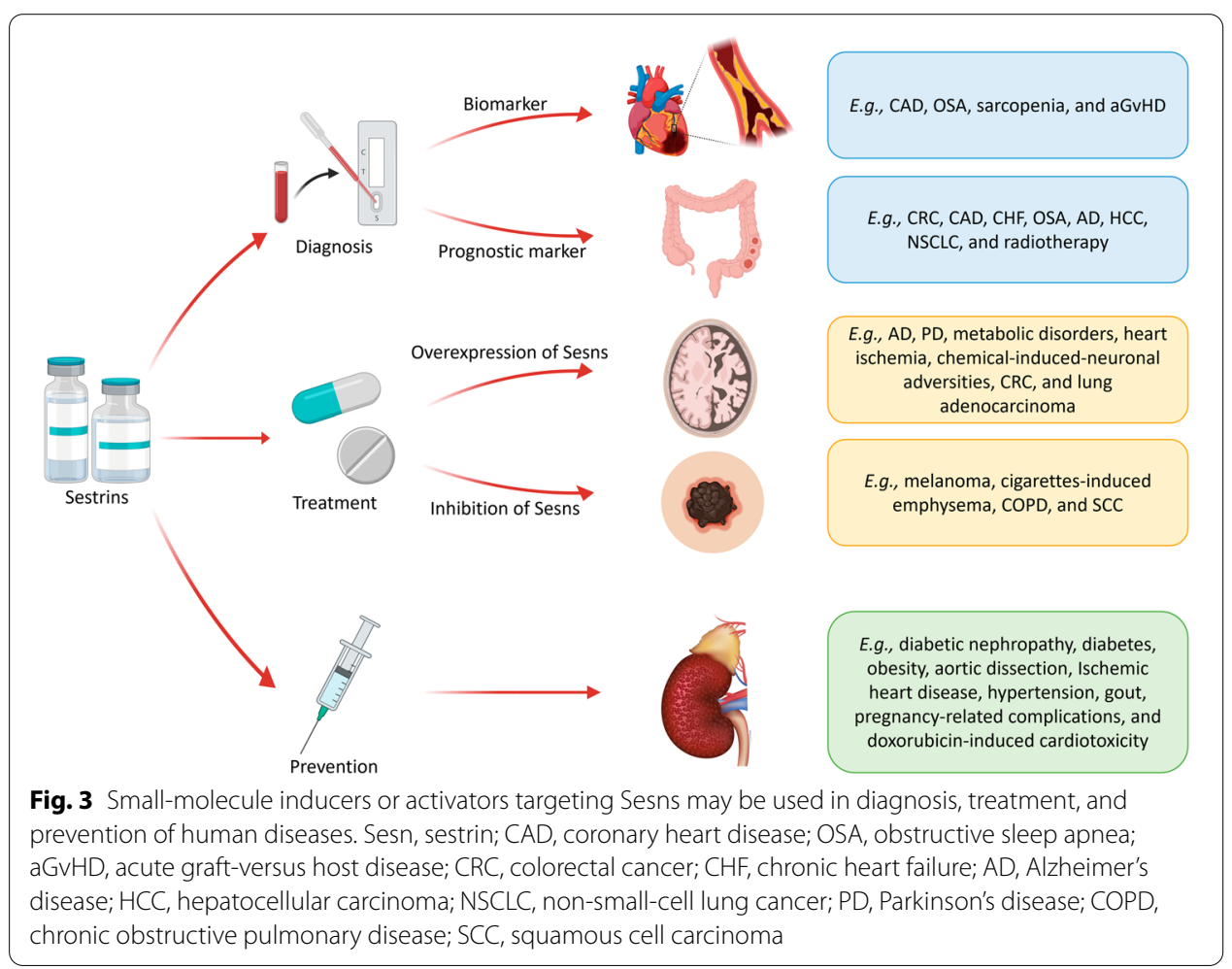


They could be used to predict poor outcomes for patients with CHF [102] or colorectal cancer $[173,180]$. Apart from that, SESN1 is associated with individual radiosensitivity, which could be utilized for predicting the toxicity of radiotherapy for cancers [181].

\section{Sesns for disease treatment}

Studies have shown that Sesns may be novel therapeutic drug targets. Small-molecule Sesns mimetics, inducers or activators might reverse pathologic conditions or diseases, such as heart ischemia, metabolic disorders, AD, PD, chemical-induced-neuronal adversities, colorectal cancer, and lung adenocarcinoma [2, 52, 182, 183]. Sesns antagonists and inhibitors or siRNA drugs that could knock down Sesns might confer therapeutic benefits for diseases such as CS-induced emphysema, COPD [123], SCC, hepatocellular carcinoma, ovarian cancer, and melanoma [53]. In addition to drugs with direct effects, Sesns could also be used to design adjuvant therapies. Based on a recent study, SESN2 might be an effective preclinical target for colorectal cancer in chemotherapy combined with nutritional supplements [184]. Pro-oxidant drugs that promote the protective effect of SESN1 in cancer cells might provide new therapeutic opportunities for cancer patients bearing the mutant TP53 gene [185]. Drugs that induce Sesns-mediated autophagy and inhibit growth of cancer cells could be a novel weapon against cancers such as human bladder cancer [186]. More importantly, Sesns might be a good target to overcome resistance of anticancer drugs, which is one of the main obstacles that influence cancer treatment [187].

In recent years, genetically modified cell sheets using virus-based or non-viral gene transfection have shown great potential in personalized and precision medicine [188]. Sesns-modified cell sheets might act as a promising preventive or therapeutic drug against aging-related diseases such as sarcopenia, cancers, AD, PD, and CAD. However, the diagnostic and therapeutic benefits of Sesns can only be obtained when its upstream and downstream pathways that underlie their biological effects are well understood.

\section{Sesns for disease prevention}

Sesns have also been reported to prevent diseases such as aortic dissection, ischemic heart disease, diabetes, insulin resistance, obesity, and hyperuricemia/gout [107, 108, 132, 189, 190]. Patients with hypertension showed elevated circulating Sesns levels, which provides a clue for preventing clinical hypertension [190]. SESN2 can also prevent pregnancy-related complications given that it was found to correct impaired trophoblast invasion, ER stress and inflammation caused by palmitate [191]. Patients with diabetic nephropathy showed decreased serum SESN2 levels; thus, measurement of SESN2 levels may be an effective approach for early detection and prevention of diabetic nephropathy [192]. Doxorubicin, a highly efficient chemotherapeutic medicine, is associated with high cardiotoxicity. A study showed that Sesns counteracted the detrimental effects of doxorubicin on cardiomyocytes, without causing cardiotoxicity [193]. It is therefore likely to be an important prevention and treatment agent against doxorubicin-induced cardiotoxicity.

Dietary restriction can increase longevity and improve health in diverse species [59]. Restriction of specific essential amino acids plays a key role, but the molecular and cellular mechanisms are still elusive [60]. Recent studies show that Sesns may be the link 
between dietary amino acids, intestinal stem cell function, gut health, and lifespan by regulating the mTOR pathway and autophagy, which could provide another clue for human disease prevention [61].

\title{
Conclusion
}

Sesns, stress-inducible metabolic proteins that repress ROS and provide cytoprotection against various noxious stimuli, have aroused great interest recently. Considering their pleiotropic functions including cellular stress elimination, AMPK promotion/mTORC1 repression, autophagy induction, pro-survival effects on normal cells as well as antiproliferative effects on cancerous cells, Sesns are key regulators of cell metabolism and contribute to cell homeostasis in physiological and pathological conditions. Owing to their antioxidant function, Sesns protect tissues in neurodegenerative disorders such as PD and AD. As an activator of AMPK and an inhibitor of mTORC1, Sesns help animals fight against various metabolic disorders, such as diabetes, obesity, cancer, atherosclerosis, and cardiac hypertrophy. Therefore, Sesns can serve as prognostic indicators and potential therapeutic targets in many disorders. Despite the protective roles of Sesns, whether uncontrolled activation of them would result in negative impacts should also be ascertained. Future studies based on transgenic animal models with silencing of Sesns should be developed to test small molecule Sesns mimetics or agonists in various diseases. Personalized medicine targeting Sesns is promisingly envisioned to develop from bench to bedside in the next generation.

\begin{abstract}
Abbreviations
AD: Alzheimer's disease; AKI: Acute kidney injury; ALS: Amyotrophic lateral sclerosis; AMI: Acute myocardial infarction; AMPK: AMP-activated protein kinase; AP-1: Activator protein 1; ARDS: Acute respiratory distress syndrome; ARE: Antioxidant responsive element; AS: Atherosclerosis; ATF4: Activating transcription factor 4; ATF6: Activating transcription factor 6; aGvHD: Acute graft-versus-host disease; C/EBPB: CCAAT/enhancer-binding protein beta; CAD: Coronary heart disease; CHF: Chronic heart failure; CHOP: CCAAT/enhancer-binding protein (C/EBP) homologous protein; COPD: Chronic obstructive pulmonary disease; CVDs: Cardiovascular diseases; DKD: Diabetic kidney disease; ECM: Extracellular matrix; ER: Endoplasmic reticulum; Erk: Extracellular signal-regulated kinase; ERs: Estrogen receptors; FoxO: Forkhead box protein O; GADD: Growth arrest and DNA damage-inducible genes; GATOR: GTPase-activating protein (GAP) activity toward Rags; HCC: Hepatocellular carcinoma; HD: Huntington's disease; HIE: Hypoxic-ischemic encephalopathy; HIF1: Hypoxiainducible factor 1; I/R: Myocardial ischemia and reperfusion; IDD: Intervertebral disc degeneration; IgE: Immunoglobulin E; IL-2: Interleukin 2; IRE1: Inositol-requiring enzyme 1; JNK: C-Jun N-terminal kinase; Keap1: Kelch-like ECH-associated protein 1; LPS: Lipopolysaccharide; MAPK: Mitogen-activated protein kinase; MCs: Glomerular mesangial cells; MPS: Muscle protein synthesis; mTOR: Mammalian target of rapamycin; mTORC1: Mechanistic target of rapamycin complex 1; mTORC2: Mechanistic target of rapamycin complex 2; NAFLD: Nonalcoholic fatty liver disease; NFATc1: Nuclear factor of activated T-cells c1; NK: Natural killer; NK-KB: Nuclear factor kappa-light-chain-enhancer of activated B cells; NLRP3: Nod-like receptor family pyrin domain containing 3; NMDA: N-methyl-D-aspartate; Nox4: NADPH oxidase 4; Nrf2: Nuclear factor erythroid 2-related factor 2; OSA: Obstructive sleep apnea; PCR: Polymerase chain reaction; PD: Parkinson's disease; PDGFRß: Platelet-derived growth factor receptor beta; PECs: Glomerular parietal epithelial cells; PERK: Protein kinase RNA-like endoplasmic reticulum kinase; PGC-1a: Peroxisome proliferator-activated receptor-gamma coactivator alpha; PHD: Prolyl hydroxylase; PI3K: Phosphoinositide 3-kinase; PKB: Protein kinase B, also known as Akt; RAGs: Recombinationactivating genes; RBX1: Ring-box 1; RNS: Reactive nitrogen species; ROS: Reactive oxygen species; S6K: Ribosomal protein S6 kinase; SCC: Squamous cell carcinoma; Sesn: Sestrin; siRNA: Small interfering RNA; SQSTM1: Sequestosome 1; SUA: Elevated serum uric acid; TGF $\beta$ : Transforming growth factor $\beta$; TLR4: Toll like receptor 4; TRAF6: TNF receptor associated factor 6; ULK1: Unc-51-like kinase 1; UPR: Unfolded protein response; VEGF: Vascular endothelial growth factor; XBP1: X-box binding protein 1; XIAP: X-linked inhibitor of apoptosis protein.
\end{abstract}

Acknowledgements

This work was supported by the Health Department of Zhejiang province fund (Grant No. 2020 RC023 and 2020KY624). This manuscript was edited for proper English language, grammar, punctuation, and spelling by one or more of the highly qualified native English-speaking editors at Freescience.

Authors' contributions

YC drafted the first version, drew figures and made tables of this manuscript. TH revised and edited this manuscript. YC and TBH retrieved literature together. ZY, QY and YW contributed to modification of tables and figures. GY, JS and JH 
reviewed and gave advice on the final version of this manuscript. All authors commented on drafts. All authors participated in the decision to submit for publication. All authors read and approved the final manuscript.

\section{Funding}

This work was supported by the Health Department of Zhejiang province fund (Grant No. 2020 RC023 and 2020KY624).

\section{Availability of data and materials}

Not applicable.

\section{Declarations}

Ethics approval and consent to participate

Not applicable.

\section{Consent for publication}

Not applicable.

\section{Competing interests}

The authors declare that they have no competing interests.

\section{Author details}

${ }^{1}$ Department of Orthodontics, Stomatology Hospital, School of Stomatology, Zhejiang University School of Medicine, Clinical Research Center for Oral Diseases of Zhejiang Province, Key Laboratory of Oral Biomedical Research of Zhejiang Province, Cancer Center of Zhejiang University, Hangzhou 310006, Zhejiang, China. ${ }^{2}$ Department of Implantology, Stomatology Hospital, School of Stomatology, Zhejiang University School of Medicine, Clinical Research Center for Oral Diseases of Zhejiang Province, Key Laboratory of Oral Biomedical Research of Zhejiang Province, Cancer Center of Zhejiang University, Hangzhou 310006, Zhejiang, China. ${ }^{3}$ Department of Oral Medicine, Stomatology Hospital, School of Stomatology, Zhejiang University School of Medicine, Clinical Research Center for Oral Diseases of Zhejiang Province, Key Laboratory of Oral Biomedical Research of Zhejiang Province, Cancer Center of Zhejiang University, Hangzhou 310006, Zhejiang, China. ${ }^{4}$ Department of Oral Pathology, Stomatology Hospital, School of Stomatology, Zhejiang University School of Medicine, Clinical Research Center for Oral Diseases of Zhejiang Province, Key Laboratory of Oral Biomedical Research of Zhejiang Province, Cancer Center of Zhejiang University, Hangzhou 310006, Zhejiang, China.

Received: 22 October 2021 Accepted: 21 December 2021

Published online: 03 January 2022

\section{References}

1. Lee JH, Budanov AV, Karin M. Sestrins orchestrate cellular metabolism to attenuate aging. Cell Metab. 2013:18:792-801.

2. Pasha M, Eid AH, Eid AA, Gorin Y, Munusamy S. Sestrin2 as a novel biomarker and therapeutic target for various diseases. Oxid Med Cell Longev. 2017;2017:3296294.

3. Sun W, Wang Y, Zheng Y, Quan N. The emerging role of Sestrin2 in cell metabolism, and cardiovascular and agerelated diseases. Aging Dis. 2020;11:154-63.

4. Buckbinder L, Talbott R, Seizinger BR, Kley N. Gene regulation by temperature-sensitive p53 mutants: identification of p53 response genes. Proc Natl Acad Sci U S A. 1994;91:10640-4.

5. Kumar A, Dhiman D, Shaha C. Sestrins: darkhorse in the regulation of mitochondrial health and metabolism. Mol Biol Rep. 2020;47:8049-60.

6. Seo K, Seo S, Ki SH, Shin SM. Sestrin2 inhibits hypoxia-inducible factor-1a accumulation via AMPK-mediated prolyl hydroxylase regulation. Free Radic Biol Med. 2016;101:511-23.

7. Kim GT, Lee SH, Kim YM. Quercetin regulates sestrin 2-AMPK-mTOR signaling pathway and induces apoptosis via increased intracellular ROS in HCT116 colon cancer cells. J Cancer Prev. 2013;18:264-70.

8. Budanov AV, Shoshani T, Faerman A, Zelin E, Kamer I, Kalinski H, et al. Identification of a novel stress-responsive gene Hi95 involved in regulation of cell viability. Oncogene. 2002;21:6017-31.

9. Saxton RA, Knockenhauer KE, Wolfson RL, Chantranupong L, Pacold ME, Wang T, et al. Structural basis for leucine sensing by the Sestrin2-mTORC1 pathway. Science. 2016;351:53-8.

10. Wolfson RL, Chantranupong L, Saxton RA, Shen K, Scaria SM, Cantor JR, Sabatini DM. Sestrin2 is a leucine sensor for the mTORC1 pathway. Science. 2016;351:43-8.

11. Huang M, Kim HG, Zhong X, Dong C, Zhang B, Fang Z, et al. Sestrin 3 protects against diet-induced nonalcoholic steatohepatitis in mice through suppression of transforming growth factor $\beta$ signal transduction. Hepatology. 2020;71:76-92.

12. Peeters $\mathrm{H}$, Debeer $\mathrm{P}$, Bairoch $\mathrm{A}$, Wilquet $\mathrm{V}$, Huysmans $\mathrm{C}$, Parthoens $\mathrm{E}$, et al. PA26 is a candidate gene for heterotaxia in humans: identification of a novel PA26-related gene family in human and mouse. Hum Genet. 2003;1 12:573-80

13. Tao $R$, Xiong $X$, Liangpunsakul S, Dong XC. Sestrin 3 protein enhances hepatic insulin sensitivity by direct activation of the mTORC2-Akt signaling. Diabetes. 2015;64:1211-23.

14. Rai N, Dey S. Protective response of Sestrin under stressful conditions in aging. Ageing Res Rev. 2020;64:101186.

15. Budanov AV, Lee JH, Karin M. Stressin' Sestrins take an aging fight. EMBO Mol Med. 2010;2:388-400.

16. Alvarez-Garcia O, Matsuzaki T, Olmer M, Masuda K, Lotz MK. Age-related reduction in the expression of FOXO transcription factors and correlations with intervertebral disc degeneration. J Orthop Res. 2017;35:2682-91. 
17. Rajan SP, Anwar M, Jain B, Khan MA, Dey S, Dey AB. Serum sestrins: potential predictive molecule in human sarcopenia. Aging Clin Exp Res. 2020;33:1315-24.

18. Zhang D-W, Wei Y-Y, Ji S, Fei G-H. Correlation between sestrin2 expression and airway remodeling in COPD. BMC Pulm Med. 2020;20:297.

19. Lovisari F, Roncon P, Soukoupova M, Paolone G, Labasque M, Ingusci S, et al. Implication of sestrin3 in epilepsy and its comorbidities. Brain Commun. 2021;3:fcaa130.

20. Shen T, Alvarez-Garcia O, Li Y, Olmer M, Lotz MK. Suppression of Sestrins in aging and osteoarthritic cartilage: dysfunction of an important stress defense mechanism. Osteoarthritis Cartilage. 2017;25:287-96.

21. Wang M, Xu Y, Liu J, Ye J, Yuan W, Jiang H, et al. Recent insights into the biological functions of sestrins in health and disease. Cell Physiol Biochem. 2017:43:1731-41.

22. Lee JH, Budanov AV, Talukdar S, Park EJ, Park HL, Park H-W, et al. Maintenance of metabolic homeostasis by Sestrin2 and Sestrin3. Cell Metab. 2012;16:311-21.

23. Ho A, Cho C-S, Namkoong S, Cho U-S, Lee JH. Biochemical basis of sestrin physiological activities. Trends Biochem Sci. 2016;41:621-32.

24. Finkel T, Holbrook NJ. Oxidants, oxidative stress and the biology of ageing. Nature. 2000;408:239-47.

25. Daenen K, Andries A, Mekahli D, van Schepdael A, Jouret F, Bammens B. Oxidative stress in chronic kidney disease. Pediatr Nephrol. 2019;34:975-91.

26. Peoples JN, Saraf A, Ghazal N, Pham TT, Kwong JQ. Mitochondrial dysfunction and oxidative stress in heart disease. Exp Mol Med. 2019;51:1-13.

27. Steven S, Frenis K, Oelze M, Kalinovic S, Kuntic M, Bayo Jimenez MT, et al. Vascular inflammation and oxidative stress: major triggers for cardiovascular disease. Oxid Med Cell Longev. 2019;2019:7092151.

28. Kattoor AJ, Pothineni NVK, Palagiri D, Mehta JL. Oxidative stress in atherosclerosis. Curr Atheroscler Rep. 2017:19:42.

29. Nascimento EB, Osler ME, Zierath JR. Sestrin 3 regulation in type 2 diabetic patients and its influence on metabolism and differentiation in skeletal muscle. Am J Physiol Endocrinol Metab. 2013;305:E1408-14.

30. Menglong W, Wan J. GW27-e0974 Increased expression of Sestrin2 in human and mice ischemic hearts. J Am Coll Cardiol. 2016;68:C34

31. Dong Z, Lin C, Liu Y, Jin H, Wu H, Li Z, et al. Upregulation of sestrins protect atriums against oxidative damage and fibrosis in human and experimental atrial fibrillation. Sci Rep. 2017;7:46307.

32. Tsilioni I, Filippidis AS, Kerenidi T, Budanov AV, Zarogiannis SG, Gourgoulianis KI. Sestrin-2 is significantly increased in malignant pleural effusions due to lung cancer and is potentially secreted by pleural mesothelial cells. Clin Biochem. 2016:49:726-8.

33. Ro S-H, Xue X, Ramakrishnan SK, Cho C-S, Namkoong S, Jang I, et al. Tumor suppressive role of sestrin2 during colitis and colon carcinogenesis. Elife. 2016;5:e12204.

34. Rai N, Kumar R, Desai GR, Venugopalan G, Shekhar S, Chatterjee P, et al. Relative alterations in blood-based levels of Sestrin in Alzheimer's Disease and mild cognitive impairment patients. J Alzheimers Dis. 2016;54:1147-55.

35. Zhang X-Y, Wu X-Q, Deng R, Sun T, Feng G-K, Zhu X-F. Upregulation of sestrin 2 expression via JNK pathway activation contributes to autophagy induction in cancer cells. Cell Signal. 2013;25:150-8.

36. Shin BY, Jin SH, Cho IJ, Ki SH. Nrf2-ARE pathway regulates induction of Sestrin-2 expression. Free Radic Biol Med. 2012;53:834-41.

37. Kumar A, Giri S, Shaha C. Sestrin2 facilitates glutamine-dependent transcription of PGC-1a and survival of liver cancer cells under glucose limitation. FEBS J. 2018;285:1326-45.

38. Chen C-C, Jeon S-M, Bhaskar PT, Nogueira V, Sundararajan D, Tonic I, et al. FoxOs inhibit mTORC1 and activate Akt by inducing the expression of Sestrin3 and Rictor. Dev Cell. 2010;18:592-604.

39. Hagenbuchner J, Kuznetsov A, Hermann M, Hausott B, Obexer P, Ausserlechner MJ. FOXO3-induced reactive oxygen species are regulated by BCL2L11 (Bim) and SESN3. J Cell Sci. 2012;125:1191-203.

40. Lee JH, Budanov AV, Park EJ, Birse R, Kim TE, Perkins GA, et al. Sestrin as a feedback inhibitor of TOR that prevents age-related pathologies. Science. 2010;327:1223-8.

41. Eid AA, Lee D-Y, Roman L, Khazim K, Gorin Y. Sestrin 2 and AMPK connect hyperglycemia to Nox4-dependent endothelial nitric oxide synthase uncoupling and matrix protein expression. Mol Cell Biol. 2013;33:3439-60.

42. Ro S-H, Nam M, Jang I, Park H-W, Park H, Semple IA, et al. Sestrin2 inhibits uncoupling protein 1 expression through suppressing reactive oxygen species. Proc Natl Acad Sci U S A. 2014;111:7849-54.

43. Yang Y, Cuevas S, Yang S, van Villar A, Escano C, Asico L, et al. Sestrin2 decreases renal oxidative stress, lowers blood pressure, and mediates dopamine D2 receptor-induced inhibition of reactive oxygen species production. Hypertension. 2014;64:825-32.

44. Sun W, Wang B, Qu X-L, Zheng B-Q, Huang W-D, Sun Z-W, et al. Metabolism of reactive oxygen species in osteosarcoma and potential treatment applications. Cells. 2019;9:87.

45. Hoeijmakers JHJ. DNA damage, aging, and cancer. N Engl J Med. 2009:361:1475-85.

46. Jackson SP, Bartek J. The DNA-damage response in human biology and disease. Nature. 2009;461:1071-8.

47. Cohen I, Idan C, Rider P, Peleg R, Vornov E, Elena V, et al. IL-1a is a DNA damage sensor linking genotoxic stress signaling to sterile inflammation and innate immunity. Sci Rep. 2015;5:14756.

48. Budanov AV, Karin M. p53 target genes sestrin1 and sestrin2 connect genotoxic stress and mTOR signaling. Cell. 2008:134:451-60.

49. Coates PJ, Lorimore SA, Wright EG. Cell and tissue responses to genotoxic stress. J Pathol. 2005;205:221-35.

50. Budanov AV. Stress-responsive sestrins link $p 53$ with redox regulation and mammalian target of rapamycin signaling. Antioxid Redox Signal. 2011;15:1679-90.

51. Sablina AA, Budanov AV, Ilyinskaya GV, Agapova LS, Kravchenko JE, Chumakov PM. The antioxidant function of the p53 tumor suppressor. Nat Med. 2005;11:1306-13.

52. Ding B, Parmigiani A, Yang C, Budanov AV. Sestrin2 facilitates death receptor-induced apoptosis in lung adenocarcinoma cells through regulation of XIAP degradation. Cell Cycle. 2015;14:3231-41.

53. Zhao B, Shah P, Budanov AV, Qiang L, Ming M, Aplin A, et al. Sestrin2 protein positively regulates AKT enzyme signaling and survival in human squamous cell carcinoma and melanoma cells. J Biol Chem. 2014;289:35806-14. 
54. Ben-Sahra I, Dirat B, Laurent K, Puissant A, Auberger P, Budanov A, et al. Sestrin2 integrates Akt and mTOR signaling to protect cells against energetic stress-induced death. Cell Death Differ. 2013;20:611-9.

55. Zoncu R, Efeyan A, Sabatini DM. mTOR: from growth signal integration to cancer, diabetes and ageing. Nat Rev Mol Cell Biol. 2011;12:21-35.

56. Kimball SR, Ravi S, Gordon BS, Dennis MD, Jefferson LS. Amino acid-induced activation of mTORC1 in rat liver is attenuated by short-term consumption of a high-fat diet. J Nutr. 2015;145:2496-502.

57. Bae SH, Sung SH, Oh SY, Lim JM, Lee SK, Park YN, et al. Sestrins activate Nrf2 by promoting p62-dependent autophagic degradation of Keap1 and prevent oxidative liver damage. Cell Metab. 2013;17:73-84.

58. Jin SH, Yang JH, Shin BY, Seo K, Shin SM, Cho IJ, Ki SH. Resveratrol inhibits LXRa-dependent hepatic lipogenesis through novel antioxidant Sestrin2 gene induction. Toxicol Appl Pharmacol. 2013;271:95-105.

59. Fontana L, Partridge L, Longo VD. Extending healthy life span-from yeast to humans. Science. 2010;328:321-6.

60. Green CL, Lamming DW. Regulation of metabolic health by essential dietary amino acids. Mech Ageing Dev. 2019;177:186-200.

61. Lu J, Temp U, Müller-Hartmann A, Esser J, Grönke S, Partridge L. Sestrin is a key regulator of stem cell function and lifespan in response to dietary amino acids. Nat Aging. 2021;1:60-72.

62. Wang L-X, Zhu X-M, Yao Y-M. Sestrin 2: its potential role and regulatory mechanism in host immune response in diseases. Front Immunol. 2019;10:2797.

63. Seo K, Ki SH, Shin SM. Sestrin2-AMPK activation protects mitochondrial function against glucose deprivationinduced cytotoxicity. Cell Signal. 2015;27:1533-43.

64. Kimball SR, Gordon BS, Moyer JE, Dennis MD, Jefferson LS. Leucine induced dephosphorylation of Sestrin2 promotes mTORC1 activation. Cell Signal. 2016;28:896-906.

65. Yang G, Shi R, Zhang Q. Hypoxia and oxygen-sensing signaling in gene regulation and cancer progression. IJMS. 2020;21:8162.

66. Pan C, Chen Z, Li C, Han T, Liu H, Wang X. Sestrin2 as a gatekeeper of cellular homeostasis: physiological effects for the regulation of hypoxia-related diseases. J Cell Mol Med. 2021;25:5341-50.

67. Olson N, Hristova M, Heintz NH, Lounsbury KM, van Vilet A. Activation of hypoxia-inducible factor-1 protects airway epithelium against oxidant-induced barrier dysfunction. Amrican journal of physiology. Lung Cell Mol Physiol. 2011;301:L993-1002.

68. Shi X, Doycheva DM, Xu L, Tang J, Yan M, Zhang JH. Sestrin2 induced by hypoxia inducible factor1 alpha protects the blood-brain barrier via inhibiting VEGF after severe hypoxic-ischemic injury in neonatal rats. Neurobiol Dis. 2016;95:111-21.

69. Hetz C, Zhang K, Kaufman RJ. Mechanisms, regulation and functions of the unfolded protein response. Nat Rev Mol Cell Biol. 2020;21:421-38.

70. Tu J, Li W, Li S, Liu W, Zhang Y, Wu X, et al. Sestrin-mediated inhibition of stress-induced intervertebral disc degradation through the enhancement of autophagy. Cell Physiol Biochem. 2018;45:1940-54.

71. Ding B, Parmigiani A, Divakaruni AS, Archer K, Murphy AN, Budanov AV. Sestrin2 is induced by glucose starvation via the unfolded protein response and protects cells from non-canonical necroptotic cell death. Sci Rep. 2016;6:22538.

72. Park H-W, Park H, Ro S-H, Jang I, Semple IA, Kim DN, et al. Hepatoprotective role of Sestrin2 against chronic ER stress. Nat Commun. 2014:5:4233.

73. Brüning A, Rahmeh M, Friese K. Nelfinavir and bortezomib inhibit mTOR activity via ATF4-mediated sestrin-2 regulation. Mol Oncol. 2013;7:1012-8.

74. Saveljeva S, Cleary P, Mnich K, Ayo A, Pakos-Zebrucka K, Patterson JB, et al. Endoplasmic reticulum stress-mediated induction of SESTRIN 2 potentiates cell survival. Oncotarget. 2016;7:12254-66.

75. Hwang H-J, Jung TW, Choi J-H, Lee HJ, Chung HS, Seo JA, et al. Knockdown of sestrin2 increases pro-inflammatory reactions and ER stress in the endothelium via an AMPK dependent mechanism. Biochim Biophys Acta Mol Basis Dis. 2017;1863:1436-44.

76. Yang Y, Guo G, Zhou W, Ge Y, Fan Z, Liu Q, Gao Y. Sestrin2 protects against bavachin induced ER stress through AMPK/mTORC1 signaling pathway in HepG2 cells. J Pharmacol Sci. 2021;145:175-86.

77. Jegal KH, Park SM, Cho SS, Byun SH, Ku SK, Kim SC, et al. Activating transcription factor 6-dependent sestrin 2 induction ameliorates ER stress-mediated liver injury. Biochim Biophys Acta Mol Cell Res. 2017;1864:1295-307.

78. Li Y, Zhang J, Zhou K, Xie L, Xiang G, Fang M, et al. Elevating sestrin2 attenuates endoplasmic reticulum stress and improves functional recovery through autophagy activation after spinal cord injury. Cell Biol Toxicol. 2020;37:401-19

79. Wang L-X, Zhu X-M, Luo Y-N, Wu Y, Dong N, Tong Y-L, Yao Y-M. Sestrin2 protects dendritic cells against endoplasmic reticulum stress-related apoptosis induced by high mobility group box-1 protein. Cell Death Dis. 2020;11:125.

80. Glick D, Barth S, Macleod KF. Autophagy: cellular and molecular mechanisms. J Pathol. 2010;221:3-12.

81. Levine B, Kroemer G. Autophagy in the pathogenesis of disease. Cell. 2008;132:27-42.

82. Peng M, Yin N, Li MO. Sestrins function as guanine nucleotide dissociation inhibitors for Rag GTPases to control mTORC1 signaling. Cell. 2014;159:122-33.

83. Maiuri MC, Malik SA, Morselli E, Kepp O, Criollo A, Mouchel P-L, et al. Stimulation of autophagy by the p53 target gene Sestrin2. Cell Cycle. 2009;8:1571-6.

84. Cordani M, Sánchez-Álvarez M, Strippoli R, Bazhin AV, Donadelli M. Sestrins at the interface of ROS control and autophagy regulation in health and disease. Oxid Med Cell Longev. 2019;2019:1283075.

85. Kim M-J, Bae SH, Ryu J-C, Kwon Y, Oh J-H, Kwon J, et al. SESN2/sestrin2 suppresses sepsis by inducing mitophagy and inhibiting NLRP3 activation in macrophages. Autophagy. 2016;12:1272-91.

86. Kumar A, Shaha C. SESN2 facilitates mitophagy by helping Parkin translocation through ULK1 mediated Beclin1 phosphorylation. Sci Rep. 2018;8:615.

87. Ishihara M, Urushido M, Hamada K, Matsumoto T, Shimamura Y, Ogata K, et al. Sestrin-2 and BNIP3 regulate autophagy and mitophagy in renal tubular cells in acute kidney injury. Am J Physiol Renal Physiol. 2013;305:F495-509. 
88. Kumar A, Shaha C. RBX1-mediated ubiquitination of SESN2 promotes cell death upon prolonged mitochondrial damage in SH-SY5Y neuroblastoma cells. Mol Cell Biochem. 2018;446:1-9.

89. Pereira BI, De Maeyer RPH, Covre LP, Nehar-Belaid D, Lanna A, Ward S, et al. Sestrins induce natural killer function in senescent-like CD8(+) T cells. Nat Immunol. 2020;21:684-94.

90. Shim Y-S, Lee S, Park H-W, Park S-R. Sestrin2 mediates IL-4-induced IgE class switching by enhancing germline $\varepsilon$ transcription in B cells. Immune Netw. 2020;20:e19.

91. Essler S, Dehne N, Brüne B. Role of sestrin2 in peroxide signaling in macrophages. FEBS Lett. 2009;583:3531-5.

92. Hu H-J, Shi Z-Y, Lin X-L, Chen S-M, Wang Q-Y, Tang S-Y. Upregulation of Sestrin2 expression protects against macrophage apoptosis induced by oxidized low-density lipoprotein. DNA Cell Biol. 2015;34:296-302.

93. Yang K, Xu C, Zhang Y, He S, Li D. Sestrin2 suppresses classically activated macrophages-mediated inflammatory response in myocardial infarction through inhibition of mTORC1 signaling. Front Immunol. 2017;8:728

94. Sundararajan S, Jayachandran I, Balasubramanyam M, Mohan V, Venkatesan B, Manickam N. Sestrin2 regulates monocyte activation through AMPK-mTOR nexus under high-glucose and dyslipidemic conditions. J Cell Biochem. 2018; 1-13.

95. Lanna A, Gomes DCO, Muller-Durovic B, McDonnell T, Escors D, Gilroy DW, et al. A sestrin-dependent Erk-Jnkp38 MAPK activation complex inhibits immunity during aging. Nat Immunol. 2017;18:354-63.

96. Ge L, Xu M, Brant SR, Liu S, Zhu C, Shang J, et al. Sestrin3 enhances macrophage-mediated generation of T helper 1 and T helper 17 cells in a mouse colitis model. Int Immunol. 2020;32:421-32.

97. Wang X, Liu W, Zhuang D, Hong S, Chen J. Sestrin2 and sestrin3 suppress NK-92 cell-mediated cytotoxic activity on ovarian cancer cells through AMPK and mTORC1 signaling. Oncotarget. 2017;8:90132-43.

98. Liu Y, Li M, Du X, Huang Z, Quan N. Sestrin 2, a potential star of antioxidant stress in cardiovascular diseases. Free Radic Biol Med. 2021;163:56-68.

99. Sun Y, Wu Y, Tang S, Liu H, Jiang Y. Sestrin proteins in cardiovascular disease. Clin Chim Acta. 2020;508:43-6.

100. Gao A, Li F, Zhou Q, Chen L. Sestrin2 as a potential therapeutic target for cardiovascular diseases. Pharmacol Res. 2020;159:104990.

101. Liu Y, Du X, Huang Z, Zheng Y, Quan N. Sestrin 2 controls the cardiovascular aging process via an integrated network of signaling pathways. Ageing Res Rev. 2020;62:101096.

102. Wang H, Li N, Shao X, Li J, Guo L, Yu X, et al. Increased plasma sestrin2 concentrations in patients with chronic heart failure and predicted the occurrence of major adverse cardiac events: a 36-month follow-up cohort study. Clin Chim Acta. 2019;495:338-44.

103. Ye J, Wang $M, X u Y$, Liu J, Jiang H, Wang Z, et al. Sestrins increase in patients with coronary artery disease and associate with the severity of coronary stenosis. Clin Chim Acta. 2017;472:51-7.

104. Budanov AV, Sablina AA, Feinstein E, Koonin EV, Chumakov PM. Regeneration of peroxiredoxins by p53-regulated sestrins, homologs of bacterial AhpD. Science. 2004;304:596-600.

105. Chen Y-R, Zweier JL. Cardiac mitochondria and reactive oxygen species generation. Circ Res. 2014;114:524-37.

106. Ma X, Liu H, Foyil SR, Godar RJ, Weinheimer CJ, Diwan A. Autophagy is impaired in cardiac ischemia-reperfusion injury. Autophagy. 2012;8:1394-6.

107. Quan N, Sun W, Wang L, Chen X, Bogan JS, Zhou X, et al. Sestrin2 prevents age-related intolerance to ischemia and reperfusion injury by modulating substrate metabolism. FASEB J. 2017;31:4153-67.

108. Quan N, Wang L, Chen X, Luckett C, Cates C, Rousselle T, et al. Sestrin2 prevents age-related intolerance to post myocardial infarction via AMPK/PGC-1 a pathway. J Mol Cell Cardiol. 2018;115:170-8.

109. Dong XC. The potential of sestrins as therapeutic targets for diabetes. Expert Opin Ther Targets. 2015;19:1011-5.

110. Liu X, Niu Y, Yuan H, Huang J, Fu L. AMPK binds to Sestrins and mediates the effect of exercise to increase insulin-sensitivity through autophagy. Metabolism. 2015;64:658-65.

111. Singh A, Kukreti R, Saso L, Kukreti S. Oxidative stress: a key modulator in neurodegenerative diseases. Molecules. 2019;24:1583.

112. Niedzielska E, Smaga I, Gawlik M, Moniczewski A, Stankowicz P, Pera J, Filip M. Oxidative stress in neurodegenerative diseases. Mol Neurobiol. 2016;53:4094-125.

113. Chen S-D, Yang J-L, Lin T-K, Yang D-I. Emerging roles of sestrins in neurodegenerative diseases: counteracting oxidative stress and beyond. J Clin Med. 2019;8:1001.

114. Chen Y-S, Chen S-D, Wu C-L, Huang S-S, Yang D-I. Induction of sestrin2 as an endogenous protective mechanism against amyloid beta-peptide neurotoxicity in primary cortical culture. Exp Neurol. 2014;253:63-71.

115. Rai N, Upadhyay AD, Goyal V, Dwivedi S, Dey AB, Dey S. Sestrin2 as serum protein marker and potential therapeutic target for Parkinson's disease. J Gerontol A Biol Sci Med Sci. 2020;75:690-5.

116. Kallenborn-Gerhardt W, Lu R, Syhr KMJ, Heidler J, von Melchner H, Geisslinger G, et al. Antioxidant activity of sestrin 2 controls neuropathic pain after peripheral nerve injury. Antioxid Redox Signal. 2013;19:2013-23.

117. Kim HJ, Joe Y, Kim S-K, Park S-U, Park J, Chen Y, et al. Carbon monoxide protects against hepatic steatosis in mice by inducing sestrin-2 via the PERK-elF2a-ATF4 pathway. Free Radic Biol Med. 2017;1 10:81-91.

118. Kim KM, Yang JH, Shin SM, Cho IJ, Ki SH. Sestrin2: a promising therapeutic target for liver diseases. Biol Pharm Bull. 2015;38:966-70.

119. Bai L, Sun C, Zhai H, Chen C, Hu X, Ye X, et al. Investigation of urinary Sestrin2 in patients with obstructive sleep apnea. Lung. 2019;197:123-9.

120. Jiang R, Wang Q, Zhai H, Du X, Sun S, Wang H. Explorating the involvement of plasma Sestrin2 in obstructive sleep apnea. Can Respir J. 2019;2019:2047674.

121. Kang Y, Chen C, Hu X, Du X, Zhai H, Fang Y, et al. Sestrin2 is involved in asthma: a case-control study. Allergy Asthma Clin Immunol. 2019;15:46.

122. Wempe F, De-Zolt S, Koli K, Bangsow T, Parajuli N, Dumitrascu R, et al. Inactivation of sestrin 2 induces TGFbeta signaling and partially rescues pulmonary emphysema in a mouse model of COPD. Dis Model Mech. 2010;3:246-53. 
123. Heidler J, Fysikopoulos A, Wempe F, Seimetz M, Bangsow T, Tomasovic A, et al. Sestrin-2, a repressor of PDGFRß signalling, promotes cigarette-smoke-induced pulmonary emphysema in mice and is upregulated in individuals with COPD. Dis Model Mech. 2013;6:1378-87.

124. Tomasovic A, Kurrle N, Sürün D, Heidler J, Husnjak K, Poser I, et al. Sestrin 2 protein regulates platelet-derived growth factor receptor $\beta$ (Pdgfr $\beta$ ) expression by modulating proteasomal and Nrf2 transcription factor functions. J Biol Chem. 2015;290:9738-52.

125. Tsilogianni Z, Baker JR, Papaporfyriou A, Papaioannou AI, Papathanasiou E, Koulouris NG, et al. Sirtuin 1: endocan and Sestrin 2 in different biological samples in patients with asthma. Does severity make the difference? J Clin Med. 2020;9:473.

126. Chai J, Wang J, Jiang R, Wang H, Zhai H, Zheng Y, et al. Diagnostic value of Sestrin2 in patients with obstructive sleep apnea. Metab Syndr Relat Disord. 2020;18:362-7.

127. Wang BJ, Wang S, Xiao M, Zhang J, Wang AJ, Guo Y, et al. Regulatory mechanisms of Sesn2 and its role in multiorgan diseases. Pharmacol Res. 2021;164:105331.

128. Hamatani H, Hiromura K, Sakairi T, Takahashi S, Watanabe M, Maeshima A, et al. Expression of a novel stress-inducible protein, sestrin 2, in rat glomerular parietal epithelial cells. Am J Physiol Renal Physiol. 2014;307:F708-17.

129. Smeets B, Huber TB. Sestrin 2: a regulator of the glomerular parietal epithelial cell phenotype. Am J Physiol Renal Physiol. 2014;307:F798-9.

130. Jia Y, Zheng Z, Yang Y, Zou M, Li J, Wang L, et al. MiR-4756 promotes albumin-induced renal tubular epithelial cell epithelial-to-mesenchymal transition and endoplasmic reticulum stress via targeting Sestrin2. J Cell Physiol. 2019;234:2905-15

131. Lin Q, Ma Y, Chen Z, Hu J, Chen C, Fan Y, et al. Sestrin-2 regulates podocyte mitochondrial dysfunction and apoptosis under high-glucose conditions via AMPK. Int J Mol Med. 2020:45:1361-72.

132. Nakatochi M, Kanai M, Nakayama A, Hishida A, Kawamura Y, Ichihara S, et al. Genome-wide meta-analysis identifies multiple novel loci associated with serum uric acid levels in Japanese individuals. Commun Biol. 2019;2:115.

133. Yang JH, Kim KM, Kim MG, Seo KH, Han JY, Ka S-O, et al. Role of sestrin2 in the regulation of proinflammatory signaling in macrophages. Free Radic Biol Med. 2015;78:156-67.

134. Lanna A, Gomes DC, Muller-Durovic B, McDonnell T, Escors D, Gilroy DW, Lee JH, Karin M, Akbar AN. A sestrin dependent Erk-Jnk-p38 MAPK activation complex inhibits immunity during aging. Nat Immunol. 2017;18:354-63.

135. O'Neill LAJ, Golenbock D, Bowie AG. The history of Toll-like receptors-redefining innate immunity. Nat Rev Immunol. 2013;13:453-60.

136. Kim MG, Yang JH, Kim KM, Jang CH, Jung JY, Cho IJ, et al. Regulation of Toll-like receptor-mediated Sestrin2 induction by AP-1, Nrf2, and the ubiquitin-proteasome system in macrophages. Toxicol Sci. 2015;144:425-35.

137. Kos N, Gradisnik L, Velnar T. A brief review of the degenerative intervertebral disc disease. Med Arch. 2019;73:421-4.

138. Vaudreuil N, Kadow T, Yurube T, Hartman R, Ngo K, Dong Q, et al. NSAID use in intervertebral disc degeneration: what are the effects on matrix homeostasis in vivo? Spine J. 2017;17:1163-70.

139. Bian Q, Ma L, Jain A, Crane JL, Kebaish K, Wan M, et al. Mechanosignaling activation of TGF $\beta$ maintains intervertebral disc homeostasis. Bone Res. 2017;5:17008.

140. Feng $C$, Liu H, Yang M, Zhang Y, Huang B, Zhou Y. Disc cell senescence in intervertebral disc degeneration: causes and molecular pathways. Cell Cycle. 2016;15:1674-84.

141. Gong C-Y, Zhang H-H. Autophagy as a potential therapeutic target in intervertebral disc degeneration. Life Sci. 2021:273:119266.

142. Boos N, Weissbach S, Rohrbach H, Weiler C, Spratt KF, Nerlich AG. Classification of age-related changes in lumbar intervertebral discs: 2002 Volvo Award in basic science. Spine (Phila Pa 1976). 2002:27:2631-44.

143. Sacitharan PK. Ageing and osteoarthritis. Subcell Biochem. 2019;91:123-59.

144. Abramoff B, Caldera FE. Osteoarthritis: pathology, diagnosis, and treatment options. Med Clin North Am 2020;104:293-311.

145. Lou Y, Wu J, Liang J, Yang C, Wang K, Wang J, Guo X. Eupatilin protects chondrocytes from apoptosis via activating sestrin2-dependent autophagy. Int Immunopharmacol. 2019;75:105748.

146. Liu S, Yu C, Xie L, Niu Y, Fu L. Aerobic exercise improves mitochondrial function in sarcopenia mice through Sestrin2 in an AMPKa2-dependent manner. J Gerontol A Biol Sci Med Sci. 2021:76:1161-8.

147. Segalés J, Perdiguero E, Serrano AL, Sousa-Victor P, Ortet L, Jardí M, et al. Sestrin prevents atrophy of disused and aging muscles by integrating anabolic and catabolic signals. Nat Commun. 2020;11:189.

148. Wolfe RR. The underappreciated role of muscle in health and disease. Am J Clin Nutr. 2006;84:475-82.

149. Yang BA, Castor-Macias J, Fraczek P, Cornett A, Brown LA, Kim M, et al. Sestrins regulate muscle stem cell metabolic homeostasis. Stem Cell Reports. 2021;16:2078-88.

150. Yoo S-Z, No M-H, Heo J-W, Park D-H, Kang J-H, Kim SH, Kwak H-B. Role of exercise in age-related sarcopenia. J Exerc Rehabil. 2018;14:551-8,

151. Martyn JAJ, Kaneki M. Muscle atrophy and the Sestrins. N Engl J Med. 2020;383:1279-82.

152. Crisol BM, Lenhare L, Gaspar RS, Gaspar RC, Muñoz VR, da Silva ASR, et al. The role of physical exercise on Sestrin 1 and 2 accumulations in the skeletal muscle of mice. Life Sci. 2018;194:98-103.

153. Kim M, Sujkowski A, Namkoong S, Gu B, Cobb T, Kim B, et al. Sestrins are evolutionarily conserved mediators of exercise benefits. Nat Commun. 2020;11:190.

154. Corrêa HL, Neves RVP, Deus LA, Reis AL, Simões HG, Navalta JW, et al. Could sestrins 2 be the secret of resistance exercise benefiting dialytic patients? Nephrol Dial Transplant. 2020;35:2198-9.

155. Zeng N, D'Souza RF, Fiqueiredo VC, Markworth JF, Roberts LA, Peake JM, et al. Acute resistance exercise induces Sestrin2 phosphorylation and p62 dephosphorylation in human skeletal muscle. Physiol Rep. 2017;5:e13526.

156. Lenhare L, Crisol BM, Silva VRR, Katashima CK, Cordeiro AV, Pereira KD, et al. Physical exercise increases Sestrin 2 protein levels and induces autophagy in the skeletal muscle of old mice. Exp Gerontol. 2017;97:17-21.

157. Wall BT, van Loon LJC. Nutritional strategies to attenuate muscle disuse atrophy. Nutr Rev. 2013;71:195-208. 
158. Li JB, Jefferson LS. Influence of amino acid availability on protein turnover in perfused skeletal muscle. Biochim Biophys Acta. 1978;544:351-9.

159. Dickinson JM, Fry CS, Drummond MJ, Gundermann DM, Walker DK, Glynn EL, et al. Mammalian target of rapamycin complex 1 activation is required for the stimulation of human skeletal muscle protein synthesis by essential amino acids. J Nutr. 2011;141:856-62.

160. Moore DR, Atherton PJ, Rennie MJ, Tarnopolsky MA, Phillips SM. Resistance exercise enhances mTOR and MAPK signalling in human muscle over that seen at rest after bolus protein ingestion. Acta Physiol (Oxf). 2011;201:365-72.

161. Tang JE, Moore DR, Kujbida GW, Tarnopolsky MA, Phillips SM. Ingestion of whey hydrolysate, casein, or soy protein isolate: effects on mixed muscle protein synthesis at rest and following resistance exercise in young men. J Appl Physiol. 1985;2009(107):987-92.

162. Parmigiani A, Nourbakhsh A, Ding B, Wang W, Kim YC, Akopiants K, et al. Sestrins inhibit mTORC1 kinase activation through the GATOR complex. Cell Rep. 2014;9:1281-91.

163. Xu D, Shimkus KL, Lacko HA, Kutzler L, Jefferson LS, Kimball SR. Evidence for a role for Sestrin 1 in mediating leucine-induced activation of mTORC1 in skeletal muscle. Am J Physiol Endocrinol Metab. 2019;316:E817-28.

164. Tsiridis E, Upadhyay N, Giannoudis P. Molecular aspects of fracture healing: which are the important molecules? Injury. 2007:38(Suppl 1):S11-25.

165. Chen J, Long F. mTOR signaling in skeletal development and disease. Bone Res. 2018;6:1.

166. Pazarci Ö, Doğan HO, Kilinç S, Çamurcu IY. Does mammalian target of rapamycin or sestrin 1 protein signaling have a role in bone fracture healing? Turk J Med Sci. 2019:49:1774-8

167. Tsukasaki M, Takayanagi H. Osteoimmunology: evolving concepts in bone-immune interactions in health and disease. Nat Rev Immunol. 2019:19:626-42.

168. Takayanagi H. The role of NFAT in osteoclast formation. Ann NY Acad Sci. 2007;1116:227-37.

169. Crockett JC, Rogers MJ, Coxon FP, Hocking LJ, Helfrich MH. Bone remodelling at a glance. J Cell Sci. 2011;124:991-8.

170. Phetfong J, Sanvoranart T, Nartprayut K, Nimsanor N, Seenprachawong K, Prachayasittikul V, Supokawej A. Osteoporosis: the current status of mesenchymal stem cell-based therapy. Cell Mol Biol Lett. 2016;21:12.

171. Oh SY, Kang N, Kang JY, Kim KW, Choi J-H, Yang Y-M, Shin DM. Sestrin2 regulates osteoclastogenesis via the p62TRAF6 interaction. Front Cell Dev Biol. 2021;9:646803.

172. Chen K-B, Xuan Y, Shi W-J, Chi F, Xing R, Zeng Y-C. Sestrin2 expression is a favorable prognostic factor in patients with non-small cell lung cancer. Am J Transl Res. 2016;8:1903-9.

173. Wei J-L, Fu Z-X, Fang M, Guo J-B, Zhao Q-N, Lu W-D, Zhou Q-Y. Decreased expression of sestrin 2 predicts unfavorable outcome in colorectal cancer. Oncol Rep. 2015:33:1349-57.

174. Shin J, Bae J, Park S, Kang H-G, Shin SM, Won G, et al. mTOR-dependent role of Sestrin2 in regulating tumor progression of human endometrial cancer. Cancers (Basel). 2020;12:2515.

175. Byun Y, Choi Y-C, Jeong Y, Lee G, Yoon S, Jeong Y, et al. MiR-200c downregulates HIF-1a and inhibits migration of lung cancer cells. Cell Mol Biol Lett. 2019;24:28.

176. Zhu G, Xu P, Guo S, Yi X, Wang H, Yang Y, et al. Metastatic melanoma cells rely on Sestrin2 to acquire anoikis resistance via detoxifying intracellular ROS. J Invest Dermatol. 2020;140:666-675.e2.

177. Byun J-K, Choi Y-K, Kim J-H, Jeong JY, Jeon H-J, Kim M-K, et al. A positive feedback loop between Sestrin2 and mTORC2 is required for the survival of glutamine-depleted lung cancer cells. Cell Rep. 2017;20:586-99.

178. Waterhouse M, Pennisi S, Pfeifer D, Deuter M, von Bubnoff N, Scherer F, et al. Colon and liver tissue damage detection using methylated SESN3 and PTK2B genes in circulating cell-free DNA in patients with acute graft-versus-host disease. Bone Marrow Transplant 2021:56:327-33.

179. Chen S, Yan W, Lang W, Yu J, Xu L, Xu X, et al. SESN2 correlates with advantageous prognosis in hepatocellular carcinoma. Diagn Pathol. 2017:12:13.

180. Huang Q-R, Pan X-B. Prognostic IncRNAs, miRNAs, and mRNAs form a competing endogenous RNA network in colon cancer. Front Oncol. 2019;9:712.

181. Palumbo E, Piotto C, Calura E, Fasanaro E, Groff E, Busato F, et al. Individual radiosensitivity in oncological patients: linking adverse normal tissue reactions and genetic features. Front Oncol. 2019;9:987.

182. Chai D, Wang G, Zhou Z, Yang H, Yu Z. Insulin increases Sestrin 2 content by reducing its degradation through the PI 3 K/mTOR signaling pathway. Int J Endocrinol. 2015;2015:505849.

183. Singh $\mathrm{P}$, Chowdhuri DK. Modulation of sestrin confers protection to $\mathrm{Cr}(\mathrm{VI})$ induced neuronal cell death in Drosophila melanogaster. Chemosphere. 2018;191:302-14.

184. Jeong S, Kim DY, Kang SH, Yun HK, Kim JL, Kim BR, et al. Docosahexaenoic acid enhances oxaliplatin-induced autophagic cell death via the ER stress/Sesn2 pathway in colorectal cancer. Cancers (Basel). 2019;11:982.

185. Cordani M, Butera G, Dando I, Torrens-Mas M, Butturini E, Pacchiana R, et al. Mutant p53 blocks SESN1/AMPK PGC-1a/UCP2 axis increasing mitochondrial O(2-) production in cancer cells. Br J Cancer. 2018;119:994-1008.

186. Liang Y, Zhu J, Huang H, Xiang D, Li Y, Zhang D, et al. SESN2/sestrin 2 induction-mediated autophagy and inhibitory effect of isorhapontigenin (ISO) on human bladder cancers. Autophagy. 2016;12:1229-39.

187. Choi SH, Hong HK, Cho YB, Lee WY, Yoo HY. Identification of Sestrin3 involved in the in vitro resistance of colorectal cancer cells to irinotecan. PLoS One. 2015:10:e0126830.

188. Jiang Z, Li N, Zhu D, Ren L, Shao Q, Yu K, Yang G. Genetically modified cell sheets in regenerative medicine and tissue engineering. Biomaterials. 2021;275:120908.

189. Xiao T, Zhang L, Huang $Y$, Shi Y, Wang J, Ji Q, et al. Sestrin 2 increases in aortas and plasma from aortic dissection patients and alleviates angiotensin II-induced smooth muscle cell apoptosis via the Nrf2 pathway. Life Sci. 2019;218:132-8

190. Fang C, Yang Z, Shi L, Zeng T, Shi Y, Liu L, et al. Circulating sestrin levels are increased in hypertension patients. Dis Markers. 2020;2020:3787295.

191. Lee S, Shin J, Hong Y, Shin SM, Shin HW, Shin J, et al. Sestrin2 alleviates palmitate-induced endoplasmic reticulum stress, apoptosis, and defective invasion of human trophoblast cells. Am J Reprod Immunol. 2020;83:e13222. 
192. Mohany KM, Al RO. Association of serum sestrin 2 and betatrophin with serum neutrophil gelatinase associated lipocalin levels in type 2 diabetic patients with diabetic nephropathy. J Diabetes Metab Disord. 2020;19:249-56.

193. Li R, Huang Y, Semple I, Kim M, Zhang Z, Lee JH. Cardioprotective roles of sestrin 1 and sestrin 2 against doxorubicin cardiotoxicity. Am J Physiol Heart Circ Physiol. 2019;317:H39-48.

194. Chantranupong L, Wolfson RL, Orozco JM, Saxton RA, Scaria SM, Bar-Peled L, et al. The Sestrins interact with GATOR2 to negatively regulate the amino-acid-sensing pathway upstream of mTORC1. Cell Rep. 2014;9:1-8.

\section{Publisher's Note}

Springer Nature remains neutral with regard to jurisdictional claims in published maps and institutional affiliations.

- fast, convenient online submission

- thorough peer review by experienced researchers in your field

- rapid publication on acceptance

- support for research data, including large and complex data types

- gold Open Access which fosters wider collaboration and increased citations

- maximum visibility for your research: over 100M website views per year

At BMC, research is always in progress.

Learn more biomedcentral.com/submissions 